\title{
The impact of the variability and periodicity of rainfall on surface water supply systems in Scotland
}

Article

Accepted Version

Afzal, M., Gagnon, A. S. and Mansell, M. G. (2016) The impact of the variability and periodicity of rainfall on surface water supply systems in Scotland. Journal of Water and Climate Change, 7 (2). pp. 321-339. ISSN 2408-9354 doi: https://doi.org/10.2166/wcc.2015.136 Available at https://centaur.reading.ac.uk/66294/

It is advisable to refer to the publisher's version if you intend to cite from the work. See Guidance on citing.

Published version at: http://jwcc.iwaponline.com/content/7/2/321

To link to this article DOI: http://dx.doi.org/10.2166/wcc.2015.136

Publisher: IWA Publishing

All outputs in CentAUR are protected by Intellectual Property Rights law, including copyright law. Copyright and IPR is retained by the creators or other copyright holders. Terms and conditions for use of this material are defined in the End User Agreement.

www.reading.ac.uk/centaur 
Central Archive at the University of Reading

Reading's research outputs online 
The impact of the variability and periodicity of rainfall on surface water supply systems in Scotland

Short title: Water resource reliability in Scotland and its links with climate variability

Muhammad Afzal $^{\mathrm{a}, \mathrm{b}}$, Alexandre S. Gagnon ${ }^{\mathrm{c}}$, and Martin G. Mansell ${ }^{\mathrm{a}}$

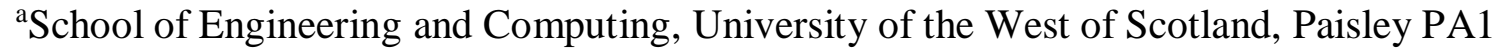
2BE, Scotland, United Kingdom

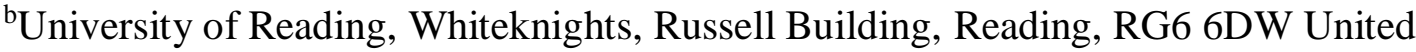
Kingdom

${ }^{\mathrm{c}}$ Centre for Environmental Research, School of Science and Sport, University of the West of Scotland, Paisley PA1 2BE, Scotland, United Kingdom

Tel: +44 (0) 141848 3270; fax: +44 (0) 141848 3289;

E-mail: Alexandre.Gagnon@uws.ac.uk

\begin{abstract}
This paper analyses the impact of the variability and periodicity of rainfall on the reliability of water supply systems in Scotland. A conceptual rainfall-runoff model was used to simulate catchment runoff and the reliability of 29 notional and six actual reservoirs was calculated using a simple storage model. The relationship between water resource reliability and the variability of rainfall was then investigated using different measures of variability. A strong correlation was found between reservoir reliability and measures representing the distribution of rainfall between the winter and summer seasons, as well as the cumulative sum (CUSUM) of annual precipitation, quantifying the variability of rainfall between years. In contrast, the intra-annual CUSUM range and the variance of monthly precipitation influenced the most the reliability of river-intake schemes. The presence of periodic patterns in rainfall anomalies was found to be more prevalent in West Scotland where reservoir reliability is on average lower than in the East. A sensitivity analysis revealed the small influence of evapotranspiration on reservoir reliability in comparison to rainfall variability. The findings indicate the measures of variability affecting the most the reliability of surface water supplies in Scotland and could therefore help with their management in the context of future climate change.
\end{abstract}

Key words: Climate variability; hydrological modelling; periodicity; reliability; Scotland; surface water supply 


\section{ABBREVIATIONS}

AMO Atlantic Multidecadal Oscillation

BADC British Atmospheric Data Centre

$\mathrm{CEH} \quad$ Centre for Ecology and Hydrology

CUSUM Cumulative summation

MIDAS Met Office Integrated Data Archive System

MORECS Met Office Rainfall and Evaporation Calculation System

NAO North Atlantic Oscillation

NSE Nash-Sutcliffe Efficiency

R-R Rainfall-runoff

SEPA Scottish Environmental Protection Agency

SST Sea Surface Temperature

WMO World Meteorological Organisation

$\mathrm{w} / \mathrm{s} \quad$ winter to summer ratio 


\section{INTRODUCTION}

Scotland receives approximately $1400 \mathrm{~mm}$ of precipitation per year averaged over the period 1914-2004 (Barnett et al., 2006). Given this abundance of precipitation and that it has increased in recent decades (Werritty and Sugden, 2012), particularly since the 1970s (Afzal et al., 2015) one would expect the reliability of water supplies not to be of concern. However, the increasing trend in annual precipitation is possibly the result of an increase in high intensity rainfall events (Fisher and Rubio, 1997, Osborn and Hulme, 2002), which have increased over the UK since the 1950s (Alexander et al., 2005). Since this increase in precipitation has taken place in winter when reservoirs are full (Osborn and Hulme, 2002), it often does not contribute to reservoir recharge (Anderson, 1997).

Moreover, there are regional variations in precipitation, resulting in an uneven distribution of water supplies across the country (Wright, 1995). Although the overall yield of developed water resources in Scotland was 32\% greater than total demand in 2005/2006 (Scottish Water, personal communication, June 2007), the majority of Scotland's population lives in the lowland belt where the yield to demand surplus is low (Adeloye and Low, 1996), and with the demand exceeding the available yield in some localised areas (Scottish Water, personal communication, June 2007). Furthermore, in the drier areas of eastern Scotland, irrigation is more common, creating further strains on water resources with rivers occasionally drying up (Adeloye and Low, 1996). An East-West asymmetry in water resources is even widening with the West becoming wetter and the East drier (Mayes, 2000).

In addition to the regional variations in precipitation and demand levels there is evidence of an increase in rainfall variability, as expected with intensification of the hydrological cycle in a warming climate (Fisher and Rubio, 1997). For example, the winter to summer (w/s) ratio 
and the intra-annual variance of precipitation have increased in Scotland during the period 1961-2000 (Afzal et al., 2015); the former is the result of winters becoming wetter and summers drier (Barnett et al., 2006). This increase in rainfall variability could outweigh the precipitation trends, potentially impacting negatively on the reliability of water resources, especially if evapotranspiration increases in a warmer climate.

Evapotranspiration is another key component of the hydrological cycle influencing catchment runoff and consequently reservoir recharge. With a warming of the atmosphere, an increase in evaporation is expected (Fisher and Rubio, 1997). Using the UK Met Office Rainfall and Evaporation Calculation System (MORECS), Kay et al. (2013) reported an increase in evapotranspiration during the period 1961-2012 across the UK, including Scotland, but noted that spatial and seasonal variations remain to be analysed. Nonetheless, climate models project an increase in evaporation in the summer under climate change (Wade et al., 2013). This increase in evaporation combined with greater variations in rainfall between seasons and from year to year as well as changes in extremes will inevitably influence catchment runoff and consequently have implications for water resource systems.

Although groundwater provides about $35 \%$ of public water supplies in England and Wales, in Scotland, approximately $93 \%$ of water resources originate from surface sources (Wright, 1995). The relatively low groundwater use in Scotland is because of its limited availability for geological reasons (Anderson, 1997), with highly productive aquifers restricted to the Southwest and Fife (MacDonald et al., 2005) where they contribute significantly to water supply. For example, in the Dumfries and Galloway region of south-western Scotland, groundwater contributes up to $20 \%$ of the total available yield (Wright, 1995). In terms of surface water supplies there are large differences in the size of the developed resources, 
ranging from Loch Lomond with a yield of 455 ML per day (Jowitt and Hay-Smith, 2002), to more than 100 operational sources each with a yield of less than 0.01 ML per day. Furthermore, more than $50 \%$ of these operational sources are from river-intake schemes that extract water directly from rivers and burns, with no storage capacity other than the catchment itself (i.e., soil moisture). Such schemes are particularly prevalent in the North of Scotland (i.e., Highland and Grampian regions) (Wright, 1995).

Climate variability plays an important role in determining the availability of water resources (Brown and Ward, 2013). The North Atlantic Oscillation (NAO) is a major source of interannual climate variability in Europe, especially during the boreal winter. It refers to the difference in atmospheric pressure at sea level between the Icelandic low and the Azores high (Hurrell, 1995). Higher than normal pressure for the Azores high compared with lower than average pressure for the Icelandic low is called a positive NAO state. During such a state, the meridional pressure gradient is enhanced, thereby leading to a predominance of westerly winds and storm tracks passing over northern Europe (Hurrell et al., 2003), including Britain (Werritty and Foster, 1998). Therefore the climate over the UK is typically wetter in a positive NAO state in comparison to a negative NAO state when it is southern Europe that experiences a wetter than average winter (Trigo et al., 2004).

Another mode of climate variability affecting the UK is the Atlantic Multidecadal Oscillation (AMO), which is an oscillation of sea surface temperatures (SST) in the North Atlantic Ocean. A positive phase of the AMO is associated with a decrease in mean sea level pressure over the North Atlantic and higher than average precipitation over the UK, particularly during the summer and autumn months. An opposite climatic signal to that of north-western Europe is observed in North America during a positive phase of the AMO (Knight et al., 2006), and 
Enfield et al. (2001) showed that the climatic impacts of the AMO influence the variability of reservoir inflows in the United States. An understanding of climate variability is thus essential to water infrastructure planning (Mason, 2010). The assessment of climatic risks to water supply systems is typically based on information gathered from historical records with the assumption that the climate is stationary (Milly et al., 2008), an approach which is unlikely to be justified under climate change. Fowler et al. (2003) suggest that the potential increase in climate variability under climate change is of greater concern to water resources than changes in mean climate.

The main inspiration behind this study is the perception that climate change is likely to increase the variability of the hydrological cycle, thus increasing uncertainty about the availability of water resources in the future. Even though Scotland is dependent on surface water supplies to meet demand, little attention has been given to date on the effect of rainfall variability on water resource systems in the country. Hence, this paper aims to improve our understanding of the role of climate variability on the reliability of water supply systems in Scotland. The objectives are (1) to examine the temporal and spatial distribution in reservoir reliability across Scotland, (2) to investigate the relationships between the reliability of water supply systems, including reservoirs and river-intake schemes, and the variability and periodicity of rainfall, and (3) to assess the contribution of variations in climatic variables other than precipitation on the reliability of water resources.

\section{METHODS}

\section{Sources of data}

Climatic data (i.e., rainfall, maximum and minimum temperatures, sunshine duration, and wind speed) were used as input variables to a Rainfall-Runoff (R-R) model. Daily 
precipitation and maximum and minimum temperature data for 40 weather stations across Scotland were obtained from the Met Office Integrated Data Archive System (MIDAS) through the British Atmospheric Data Centre (BADC) (UK Meteorological Office, 2006). Figure 1 depicts the location of the 40 weather stations with further information about those weather stations provided in Table 1. Also shown are the three climatological regions of Scotland as defined by Barnett et al. (2006), i.e., North, West, and East Scotland. As noted in previous research (e.g. Sweeney and O'Hare (1992)), the network of precipitation gauges is highest in southern and central Scotland where the majority of the population resides and sparse in North Scotland. Daily wind speed data were also obtained from MIDAS but from only five of the above weather stations (Figure 2). Daily sunshine duration data interpolated on a $5 \mathrm{~km}$ x $5 \mathrm{~km}$ grid were obtained from the baseline (1961-1990) dataset of the UK Climate Impacts Programme for the 21 grid cells corresponding to the location of the weather stations analysed in Afzal et al. (2015), which is a subset of the stations shown in Figure 1.

Figure 2 depicts the location of the river catchments, the river-intake schemes, and the case study reservoirs with their storage volume. The selection of the eight catchments whose data were used to calibrate the R-R model was based on the availability of river flow data for a minimum continuous period of 10 years and the quality of the climatic data at a weather station located in close proximity to a gauged catchment. Small catchments were preferred for the model calibration given the dependence of Scotland on water supplies from small rivers (Smith, 1977). This is because the majority of reservoirs in the UK are in upland areas and are therefore fed by rivers with small catchments (Orr et al., 2008). It was also aimed to have a reasonable spread of catchments across Scotland. The Scottish Environmental Protection Agency (SEPA) and the Centre for Ecology and Hydrology (CEH) provided the daily river flow data for the eight catchments (Table 2). 
Scottish Water provided daily water abstraction data for two river-intake schemes for the period 2009-2012 as well as data on the mean annual inflow, the mean annual demand, and the storage capacity of six case study reservoirs. The selection of the reservoirs was based on their storage volume in comparison to mean annual inflow, i.e., the storage ratio, and the average daily demand in relation to mean annual inflow, i.e., the demand ratio. The selection process aimed at choosing a number of reservoirs that would cover a wide range of storage and demand ratios, as shown in figure 3, as well as different parts of Scotland.

The selected reservoirs were provided from a list of reservoirs referred to as drought reservoirs (Scottish Water, personal communication, July 2011). Hence, these reservoirs are not representative of all reservoirs across Scotland but represent reservoirs at greater risk of failure because they are relatively small and/or independent. Small and independent reservoirs are more sensitive to changes in climate variability than large reservoirs (Marsh and Turton, 1996). Had only large reservoirs been selected, e.g. Loch Lomond, the number of failures would have been limited, making it difficult to examine the relationships between reservoir reliability with different measures of rainfall variability.

\section{The conceptual R-R model}

A conceptual R-R model was used to generate catchment runoff, which then served as input into a reservoir model. Model generated runoff was used so that the effect of various patterns of rainfall could be investigated and because long records of reservoir inflow are scarce in Scotland and even unavailable for many reservoirs (Jowitt and Hay-Smith, 2002). In order to investigate the effect of reservoir characteristics on reliability, the concept of notional reservoirs was used. A notional reservoir was considered to be a hypothetical reservoir that is not connected to other sources and which has arbitrary storage and demand characteristics. 
The R-R model was based on the probability distribution model described in Moore (2007, 1985), which is widely used in the UK (Christierson et al., 2012). It determines the change in soil moisture storage using a simple water balance approach, i.e., the storage volume increases due to precipitation and decreases due to evapotranspiration. Potential evapotranspiration was estimated using the modified Penman-Monteith equation outlined in Allen et al. (1998).

The R-R model has five parameters that require having values assigned by calibration with respect to observed flow data. The calibration and validation was carried out using a minimum period of five years each. A number of statistical indices exist to compare simulated and observed data. This study used the Nash-Sutcliffe efficiency (NSE) coefficient, as it is one of the most widely used techniques to assess the performance of hydrological models (Singh et al., 2010). The values of the NSE coefficient can range from $-\infty$ to 1 with a value of one indicating a perfect match, and a value of zero indicating that the model predictions are as accurate as the average of the observed data, that is, making a perpetual forecast of average conditions (Nash and Sutcliffe, 1970).

Krause et al. (2005) indicated that extreme values in a time series can result in a poor NSE coefficient because hydrological models tend to underestimate river flow during peak flows. For this reason, they suggested calculating the NSE coefficient with logarithmic values:

$\ln N S E=1-\frac{\sum_{i=1}^{n}\left(\ln O_{i}-\ln S_{i}\right)^{2}}{\sum_{\mathrm{i}=1}^{\mathrm{n}}\left(\ln O_{i}-\ln \overline{\mathrm{O}}\right)^{2}}$

where $O_{i}$ and $S_{i}$ refer to the observed and simulated river flow data, respectively, and $\bar{O}$ is the mean of the observed data. By applying the logarithmic values, the peak flows tend to be flattened while low values remain unchanged; consequently, the influence of low flow values increases and that of very high flow values decreases (Krause et al., 2005). 
The river flow time series were divided into two with the first half used to calibrate the model and the second half to validate it. The calibration procedure consisted of adjusting manually the five tuneable parameters to achieve the best model fit.

\section{Reservoir model and reliability analysis}

The operation of the reservoirs was modelled using a simple tank model with the storage volume of a reservoir; $S$, at time step $t+1$ calculated using the following equation:

$S_{t+1}=S_{t}+Q_{t}-D_{t} \quad\left(\right.$ if $\left.S_{t}<S_{\max }\right)$

$S_{t+1}=S_{\max }$ otherwise

where $Q_{t}$ and $D_{t}$ are the inflow and outflow into and out of the reservoir, respectively. For simplicity, it is assumed that the net precipitation (precipitation - evaporation) on the reservoir surface as well as seepage into groundwater is negligible.

For every year, the time-based reliability, $R$, of the reservoirs was calculated as:

$R=\left(1-\frac{N_{f}}{365}\right) * 100$

where $N_{f}$ is the number of failure days. A 'failure' was arbitrarily defined to have occurred when the reservoir volume fell below $30 \%$ capacity, as supply restrictions are often initiated when this threshold volume is reached (Kiem and Franks, 2003). For the two river-intake schemes a 'failure' was recorded when the river flow after abstraction was less than the Q95 (i.e., the flow exceeded $95 \%$ of the time and in this case calculated over four years), with abstraction assumed to be constant between years and calculated using data for the period 2009-2012. The Q95 is widely used to guide abstraction and consent policies in the UK (Scottish Environment Protection Agency, 1997), and is a good proxy measure of "drought" runoff, as used in the UK Climate Change Risk Assessment (Arnell et al., 2014). 
Three important characteristics of a reservoir are its storage volume, annual inflow, and annual demand. The storage volume and annual demand can be expressed as nondimensional ratios by dividing them by the mean annual inflow. Hence, the storage factor was defined by:

$S_{f}=\frac{S}{Q_{a v} \times 365}$

where $S$ is the storage volume of the reservoir and $Q_{a v}$ is the average daily inflow. This storage ratio is a good indicator of the resilience of a water supply system to climate variability with systems having a large volume of storage in comparison to their inflow more likely to be able to withstand a prolonged drought (Smith and Bennett, 1994). The demand ratio was defined by:

$D_{f}=\frac{Q_{d}}{Q_{a v}}$

where $Q_{d}$ is the average daily demand. The storage and demand ratios of all case study reservoirs remained between 0 and 1 (Figure 3).

To examine the temporal variability in the reliability of the notional reservoirs, the precipitation time series at each of the 40 weather stations was divided into three time-periods of 15 years each, i.e., 1961-1975, 1976-1990, and 1991-2005. Then, the reliability of 29 notional reservoirs consisting of different combinations of storage and demand ratios (i.e., one for each combination of storage and demand ratio varying from 0 to 1.0 with an interval of 0.2 ) was calculated using the above rainfall datasets. The mean characteristics of the eight calibrated R-R models were used to simulate the inflow into the notional reservoirs. At each weather station the mean reliability value was computed for each of the three time-periods. 
The mean reliability for each combination of storage and demand ratio is shown as a contour plot in Figure 3, together with the reliability of the six actual reservoirs. The Knockquhassen, Loch Calder, and Dhu Loch reservoirs have, on average, over $80 \%$ reliability, whereas the Glendevon reservoir, located in a drier part of Scotland, has the lowest reliability of the six actual reservoirs due to its low storage ratio and high demand ratio. This study assumed a constant storage and demand ratio; however, these could vary between years. This is because both the storage and demand ratios are a function of reservoir inflow and the demand ratio is also calculated using the average daily demand.

\section{Measures of variability}

The following nine measures of rainfall variability were computed:

Variability within a year: intra-annual variance, intra-annual cumulative summation (CUSUM) range, w/s ratio, and ratios of winter and summer precipitation to total annual precipitation.

Variability from year to year: coefficient of variation, CUSUM of annual precipitation, annual number of dry days, and average length of a dry spell per year. A dry day was defined when precipitation was less than $0.2 \mathrm{~mm}$ (Afzal et al., 2015) or when the effective rainfall was equal to zero.

The intra-annual variance of precipitation was calculated using monthly precipitation totals, as daily data include days without any precipitation, which would result in a distorted variance value. The CUSUM refers to the cumulative sum of differences between the values of a time series and its average. For example, let $X_{1}, X_{2}, \ldots, X_{365}$ represent the daily values of an annual precipitation time series and ${ }^{-}$the mean of that time series. From this, the cumulative sums, $S$, are calculated using the following equation: 
$S_{i}=S_{i 1}+\left({ }_{i}-\right)$

for $i=1,2, \ldots, 365$. The cumulative sum begins with $\mathrm{S}_{0}=0$ and because the average is subtracted from each value, the cumulative sum also ends at zero $\left(S_{365}=0\right)$. For each year, the annual CUSUM range was calculated by subtracting the maximum CUSUM value from the minimum CUSUM value. Thus, the intra-annual CUSUM range is a measure of the temporal distribution of rainfall within a year with a small value meaning that rainfall is more uniformly distributed throughout the year (Afzal et al., 2015). Both the intra-annual variance and the intra-annual CUSUM range were normalised by dividing by the square of the mean and the mean, respectively.

Seasonal changes in precipitation were calculated using the w/s ratio of precipitation, which in this study is defined as the ratio of average precipitation from December through February to average precipitation during the June-August season.

The CUSUM of annual precipitation was also computed using equation 6 but with $\mathrm{X}_{\mathrm{i}}$ and representing individual values in a total annual precipitation time series and average annual precipitation over a 20-year period, respectively. Hence the CUSUM of annual precipitation shows how individual values compare to the 20-year average. During periods when total annual precipitation is below average, the CUSUM will decrease, while it will increase when annual precipitation values are above the 20 -year average.

\section{Periodicity of rainfall}

The above measures of rainfall variability represent semi-random variations within a year and from year to year and have limited use in describing periodic variations. Where there is a periodic variation in rainfall the amount of storage required is a function of both the 
amplitude and the period of variation. The reliability of reservoirs can therefore be expected to be proportional to both the period and amplitude of such variations. This is represented in Figure 4, which illustrates the decrease in reliability for a simple cosine input of different periods for different storage ratios.

The presence of regular periodic variations in the precipitation time series was therefore investigated using autocorrelation and Fourier analysis at 21 of the 40 weather stations for the period 1961-2000. The latter represents the amplitude of variations in terms of the spectral energy and periods by the predominant frequency peaks. The precipitation data were expressed as standardised residuals from a linear trend line calculated using the least squares approach. The removal of a linear trend prior to plotting the autocorrelation function and the periodogram was necessary in order to meet the stationarity requirements of the two techniques, while the use of anomalies ensured that the annual cycle did not dominate the spectral signal. In the periodogram, the peak periodicity in each of the three ranges of frequency depicted in Figure 5 was identified.

\section{Relationship between reliability of water supply systems and the variability and periodicity of rainfall}

To investigate the relationship between rainfall variability and reservoir reliability, the rainfall time series of each of the 40 weather stations were divided into time-periods of 20 to 30 years (depending on the length of data records available), creating a total of 87 rainfall datasets. The reliability of a notional reservoir having the mean storage and demand ratio of the six case study reservoirs was calculated for each rainfall dataset (and as above using the mean characteristics of the eight calibrated R-R models to simulate reservoir inflow). The 
reliability datasets were then correlated with nine measures of variability, which were constructed using the rainfall datasets, for the same time-periods.

A visual inspection was performed to determine whether there is any association between reservoir reliability and the peak periodicities calculated over the same time-period in terms of both the amplitude and period of the variation. In addition, the reliability of the two riverintake schemes was calculated at the annual time-scale during the periods 1976-2005 and 1963-2005 for the Strontian and Killicrankie rivers, respectively, and was then compared with the variability of rainfall at the nearest weather station.

\section{Re-sequencing of the rainfall time series}

In order to investigate further the relationship between extreme rainfall patterns and the reliability of both storage reservoirs and river-intake schemes, a number of semi-artificial rainfall patterns were created by re-arranging the rainfall data. This was done to examine the influence of droughts over periods longer than seen during the study period on reliability. The re-sequencing was performed on effective rainfall data; consequently, other meteorological data such as sunshine duration, and maximum and minimum temperatures, which were used to estimate evapotranspiration, did not have to be re-sequenced separately. The method consisted of increasing the concentration of rainfall into two, three, four, and five rainy periods in each year by breaking the daily rainfall data over a year into equal continuous periods of rains separated by dry periods of the same length. As an example, Figure 6 illustrates the re-sequenced effective rainfall time series at Balmoral.

\section{The effect of evapotranspiration on the reliability of water supply systems}


Evapotranspiration was estimated from maximum and minimum temperature and sunshine duration data obtained from 21 weather stations across Scotland, in addition to wind speed, which was assumed to be constant at $2.5 \mathrm{~ms}^{-1}$. This subset of the 40 weather stations was selected because the climatic variables used to calculate evapotranspiration were only available at those weather stations. The analysis was performed over the period 1961-1990 given the availability of the sunshine duration data during that period only.

In the first instance, a sensitivity analysis was performed to assess the influence of each climatic variable on the estimate of evapotranspiration. Then, to determine the effect of changes in evapotranspiration on reservoir reliability, evapotranspiration was arbitrarily increased by $5 \%$ and the resulting change in reliability was calculated. Kay et al. (2013) calculated that evaporation has increased in Scotland by approximately $0.6 \mathrm{~mm} /$ year during the period 1961-2012. This corresponds to about $0.13 \% / y e a r$, meaning that a $5 \%$ increase in evaporation would be expected to be reached in three to four decades if the trend were to continue at the same rate. Nonetheless, other factors affect changes in evapotranspiration such as land use and vegetation type, and urbanisation.

\section{RESULTS AND DISCUSSION}

\section{Calibration and validation of the $R-R$ model and sensitivity to the tuneable parameters}

A summary of the results of the calibration and validation of the R-R model is shown in

Table 2. It can be seen that the calibration of the R-R model resulted in positive values of the NSE coefficient for all eight catchments. Figure 7a shows that the simulated flow of the River Black Cart compares very well with the observed flow for a single year while Figure $7 \mathrm{~b}$ shows the general relationship for a longer period with a higher correlation seen for the very low flows and very high flows. The model performance was considered satisfactory given 
that it is modelling the effect of a variety of catchment characteristics such as topography and the conductivity, porosity, and storage capacity of the soil, the vegetation, and land use (Mansell, 2003), all of which affect the partitioning between evapotranspiration, infiltration, and soil moisture storage (Brown and Ward, 2013).

The sensitivity of the model to the changes in the values of the five calibrated parameters showed that the model is most sensitive to changes in the value of the translation diffusion coefficient, $\lambda$, with a $5 \%$ increase in the value of that variable resulting in a change in runoff greater than $2 \%$. The percentage change in runoff resulting from a $5 \%$ change in the value of each of the four other tuneable parameters resulted in an increase/decrease in runoff of $0.5 \%$ or less (Figure 8).

\section{Spatial and temporal patterns in the reliability of notional reservoirs}

A clear East-West pattern is seen in the average reliability of the notional reservoirs during the period 1976-1990 with higher reliability values observed in the East than in the West (Figure 1). This spatial pattern in reservoir reliability reflects the spatial distribution of rainfall variability across the country with reliability being lower in the West where rainfall is on average more variable than in the East (Afzal et al., 2015). In addition, reservoir reliability has decreased slightly over time from an average of 79\% during the period 1961-1975 for Scotland as a whole to $77 \%$ during the period 1976-1990, and further decreased to $76 \%$ during the period 1991-2005 (Figure 9). The highest decrease was observed in the West, although 1976-1990 and 1991-2005 have almost identical means. An examination of the temporal changes at three locations with longer data records showed that reservoir reliability has decreased overall during the period 1931-2005, showing that the decrease in reliability 
seen in recent decades is a continuation of a trend that started a few decades earlier (Figure 10).

\section{Relationship between reliability of water supply systems and rainfall variability}

In view of the range of variables measuring different aspects of rainfall variability, it is useful to investigate which variables are most closely connected with reservoir performance. Eight out of the nine measures of rainfall variability showed a statistically significant correlation with the average reliability of the six case study reservoirs. The strongest correlation is seen for the w/s ratio of precipitation (Figure 11a). It was found that both an increase in summer rainfall as a proportion of total annual precipitation and a decrease in winter precipitation as a proportion of total annual precipitation increase reservoir reliability (Figure 11b), which reflects the fact that water supply systems are more likely to fail during the summers months in the UK when precipitation is less and the demand higher. The combined effect on reservoir reliability of precipitation during all seasons as observed using the normalised CUSUM of annual precipitation was slightly weaker, although still statistically significant (Figure 11c). A relationship of similar magnitude was seen between the normalised intra-annual variance of precipitation and reservoir reliability (Figure 11d).

A statistically significant correlation was also observed between reservoir reliability and measures representing the variability of rainfall between years. A strong relationship was noted with the normalised CUSUM of annual precipitation range (Figure 11e), although it is weaker than for the w/s ratio, while the coefficient of variation showed a weak correlation with reservoir reliability (Figure 11f). The annual number of dry days was unexpectedly found to be positively correlated with reservoir reliability (Figure 11g), although the relationship is weak. This could be due to the sequences of dry days within a year, which can 
be made up of many short dry periods, which have little impact on reservoir reliability. There is also a possibility that this could be the impact of more precipitation but coming from fewer wet days. Figure $11 \mathrm{~h}$, which includes re-sequenced rainfall data, shows that there is no significant relationship between reservoir reliability and the average length of a dry spell in a year.

The above analysis demonstrated that the measures related to the distribution of rainfall within the year were seen to be the best indicators of rainfall variability with regards to the reliability of storage reservoirs in Scotland. These included the w/s ratio of precipitation and the proportion of summer rainfall to total annual precipitation. Some measures related to the variability of rainfall from year to year were also found to influence significantly reservoir reliability, in particular, the CUSUM of annual precipitation, suggesting the potential influence of rainfall periodicities on reservoir reliability.

The w/s precipitation ratio was not seen to influence significantly the reliability of the riverintake schemes (Figure 12a), nor did the ratios of winter or summer precipitation to total annual precipitation (Figures 12b,c). The normalised intra-annual CUSUM range and the intra-annual variance showed the strongest correlation with the reliability of both river-intake schemes (Figures 12d,e). This indicates that the distribution of rainfall during the year and its variability between months are the most important variables influencing the reliability of the river-intake schemes in Scotland. No statistically significant correlation was seen with either the number of dry days per year or the average dry spell length.

\section{Relationship between reliability of water supply systems and the periodicity of rainfall}


Figure 13 shows that many weather stations exhibit statistically significant autocorrelation coefficients at different lags in the monthly precipitation anomaly time series. Repeating patterns in rainfall anomalies appear to be particularly dominant in West Scotland and many weather stations experience positive autocorrelation at lags between eight and 14 months and between 18 and 20 months (see Figure 1 for the depiction of the three regions of Scotland). A similar spatial pattern is seen in the spectral analyses, which show that weather stations with greater spectral energy prevail in West Scotland (Figure 14), where reservoir reliability is, on average, lower than in the East (Figure 1).

The peak energy level of the longer-term periodicities appear to be stronger than the shorter term periodicities (Figure 14), which is also shown by the limited number of weather stations having significant autocorrelation at lags of less than eight months (without considering lagone). Figure 14 also shows that the East-West asymmetry in the amplitude of the periodicities, as represented by the energy spectrum, is similar for the three categories of periods of variations, i.e., less than six months, between six and 12 months, and longer than 12 months.

One would expect reservoir reliability to decrease as a result of an increase in the amplitude of the inflow and/or an increase in the period of variation. This analysis has demonstrated that the lower reservoir reliability seen in the West is associated with the presence of significant periodicities in rainfall anomalies as shown by autocorrelation and spectral analyses. In the East the autocorrelation coefficients were not as statistically significant and the amplitude of the periodicities, as represented by the peak energy spectrum, was found to be much weaker than in the West. 


\section{Relationship between reliability of water supply systems and evapotranspiration}

The sensitivity analysis of the components of evapotranspiration model revealed that sunshine duration is the climatic variable which has the greatest influence on evapotranspiration, but temperature is also significant (Table 3), which is consistent with the work of Gao et al. (2006) in China. Due to the limited availability of wind speed data at many weather stations, a constant wind speed value was used; nonetheless, wind speed was found to influence the estimate of evapotranspiration, but less significantly than the other climatic variables.

It was also shown that a 5\% increase in evapotranspiration in the R-R model (keeping rainfall unchanged) decreased reservoir reliability by less than $1 \%$ with the exception of one timeperiod at one reservoir (Figure 15). This is because this $5 \%$ change in evapotranspiration resulted in a decrease in runoff of only $1.4 \%$, whereas the same percentage change in rainfall increased runoff by $6.6 \%$. This suggests that the influence of evapotranspiration is weak in comparison to that of rainfall, although such a modest percentage change is about the same magnitude as the changes in the reliability of storage reservoirs experienced in Scotland during the period 1961-2005.

\section{CONCLUSIONS}

The motivation of this study is that a warmer climate under global warming might intensity the water cycle through an increase in the occurrence of extreme events such as floods and droughts, thereby potentially leading to changes in water resource availability. Trends in global precipitation and evapotranspiration suggest that an acceleration of the hydrological cycle is already occurring with higher evapotranspiration rates in the summer months leading to the drying of soils and vegetation (Huntington, 2006). An increase in rainfall variability, 
including the presence of periodicities, is of particular concern to Scotland whose water supply originates mostly from surface sources. Hence this paper provided an insight of the relative importance of climate variability on the reliability of water resource systems in Scotland. It was found that the temporal distribution of rainfall within a year and in particular the w/s ratio influences significantly reservoir reliability. In addition, reservoir reliability was found to be influenced by variations in precipitation from year to year as measured by the CUSUM of annual precipitation. However, the w/s ratio was found not to influence significantly the reliability of river-intake schemes, which was rather related to variations in the intra-annual CUSUM range and the intra-annual variance of precipitation. In addition, the presence of periodic patterns in rainfall anomalies were found to be more prevalent in the West and accordingly reservoir reliability is, on average, lower in the West than in other parts of Scotland.

However, the results of this study do not foresee an alarming trend in water supply reliability across Scotland as the decrease in reliability seen over the last few decades has yet been modest in comparison to the percentage of water lost through leakage, for example, the latter accounting for $34 \%$ of the water abstracted nationally (Scottish Water, personal communication, July 2013). Nevertheless climate models predict enhanced seasonality under climate change (i.e., wetter winters and drier summers) and bearing in mind the significance of the w/s ratio observed in this study, a decrease in the yield to demand ratio might become a concern in some localised areas, particularly if climate change also leads to an increase in the demand for water (Arnell, 1998). An increase in variability at shorter time-scale, as represented by the variance of precipitation between months, under climate change would also negatively impact on the supply of water from river-intake schemes, which is the main source of water in many parts of the country. Further research is under way to assess how 
climate variability is projected to change under climate change and its potential impacts on the reliability of water supply systems in Scotland.

\section{ACKNOWLEDGEMENTS}

The authors wish to thank the British Atmospheric Data Centre (BADC) for the climatic data and CEH and SEPA for providing the river flow data. We are also thankful to Dr Owen Bramwell and Mary Lynch from Scottish Water for providing the required reservoir and river-intake scheme data. A.S. Gagnon acknowledges financial support from the Scottish Alliance for Geoscience, Environment and Society (SAGES).

\section{REFERENCES}

ADELOYE, A. J. \& LOW, J. M. 1996. Surface-water abstraction controls in Scotland. Journal of the Chartered Institution of Water and Environmental Management, 10, 123-129.

AFZAL, M., GAGNON, A. S. \& MANSELL, M. G. 2015. Changes in the variability and periodicity of precipitation in Scotland. Theoretical and Applied Climatology, 119, 135-159.

ALEXANDER, L. V., TETT, S. F. B. \& JONSSON, T. 2005. Recent observed changes in severe storms over the United Kingdom and Iceland. Geophysical Research Letters, 32, L13704.

ALLEN, R. G., PEREIRA, L. S., RAES, D. \& SMITH, M. 1998. Crop evapotranspiration Guidelines for computing crop water requirements Rome: Food and Agriculture Organization (FAO) of the United Nations.

ALLEN, R. G., PRUITT, W. O., WRIGHT, J. L., HOWELL, T. A., VENTURA, F., SNYDER, R., ITENFISU, D., STEDUTO, P., BERENGENA, J., YRISARRY, J. B., SMITH, M., PEREIRA, L. S., RAES, D., PERRIER, A., ALVES, I., WALTER, I. \& ELLIOTT, R. 2006. A recommendation on standardized surface resistance for hourly calculation of reference ETO by the FAO56 Penman-Monteith method. Agricultural Water Management, 81, 1-22.

ANDERSON, P. 1997. Demands and resources for public water supplies in Scotland from 1991 to 2016. Journal of the Chartered Institution of Water and Environmental Management, 11, 164-169.

ARNELL, N. W. 1998. Climate change and water resources in Britain. Climatic Change, 39, 83-110.

ARNELL, N. W., CHARLTON, M. B. \& LOWE, J. A. 2014. The effect of climate policy on the impacts of climate change on river flows in the UK. Journal of Hydrology, 510, 424-435.

ARNELL, N. W. \& REYNARD, N. S. 1996. The effects of climate change due to global warming on river flows in Great Britain. Journal of Hydrology, 183, 397-424. 
BARNETT, C., HOSSELl, J., PERRY, M., PROCTER, C. \& HUGHES, G. 2006. Patterns of climate change across Scotland: Technical Report, Edinburgh, Scotland \& Northern Ireland Forum for Environmental Research.

BROWN, C. \& WARD, M. N. 2013. Managing Climate Risk in Water Supply Systems, London, IWA Publishing.

CHRISTIERSON, B. V., VIDAL, J.-P. \& WADE, S. D. 2012. Using UKCP09 probabilistic climate information for UK water resource planning. Journal of Hydrology, 424-425, 48-67.

ENFIELD, D. B., MESTAS-NUNEZ, A. M. \& TRIMBLE, P. J. 2001. The Atlantic Multidecadal Oscillation and its relation to rainfall and river flows in the continental U.S. Geophysical Research Letters, 28, 2077-2080.

FISHER, A. C. \& RUBIO, S. J. 1997. Adjusting to climate change: Implications of increased variability and asymmetric adjustment costs for investment in water reserves. Journal of Environmental Economics and Management, 34, 207-227.

FOWLER, H. J., KILSBY, C. G. \& O'CONNELL, P. E. 2003. Modeling the impacts of climatic change and variability on the reliability, resilience, and vulnerability of a water resource system. Water Resources Research, 39, 1222.

GAO, G., CHEN, D., REN, G., CHEN, Y. \& LIAO, Y. 2006. Spatial and temporal variations and controlling factors of potential evapotranspiration in China: 1956-2000. Journal of Geographical Sciences, 16, 3-12.

HUNTINGTON, T. G. 2006. Evidence for intensification of the global water cycle: Review and synthesis. Journal of Hydrology, 319, 83-95.

HURRELL, J. W. 1995. Decadal trends in the North Atlantic Oscillation and relationships to regional temperature and precipitation. Science, 269, 676-679.

HURRELL, J. W., KUSHNIR, Y., OTTERSEN, G. \& VISBECK, M. 2003. An overview of the North Atlantic Oscillation. Geophysical Monograph Series, 134, 1-35.

JOWITT, P. W. \& HAY-SMITH, D. 2002. Reservoir yield assessment in a changing Scottish environment. Sci Total Environ, 294, 185-99.

KAY, A. L., BELL, V. A., BLYTH, E. M., CROOKS, S. M., DAVIES, H. N. \& REYNARD, N. S. 2013. A hydrological perspective on evaporation: historical trends and future projections in Britain. Journal of Water and Climate Change, 4, 193-208.

KIEM, A. S. \& FRANKS, S. W. 2003. Elevated drought risk due to multi-decadal climate variability. In: BLOSCHL, G., FRANKS, S., KUMAGAI, M., MUSIAKE, K. \& ROSBJERG, D. (eds.) Water Resources Systems - Hydrological Risk, Management and Development. Wallingford, Oxfordshire, UK: IAHS Press, Centre for Ecology and Hydrology.

KNIGHT, J. R., FOLLAND, C. K. \& SCAIFE, A. A. 2006. Climate impacts of the Atlantic Multidecadal Oscillation. Geophysical Research Letters, 33, L17706.

KRAUSE, P., BOYLE, D. P. \& BÄSE, F. 2005. Comparison of different efficiency criteria for hydrological model assessment. Advances in Geosciences, 5, 89-97.

MACDONALD, A. M., ROBINS, N. S., BALL, D. F. \& DOCHARTAIGH, B. E. O. 2005. An overview of groundwater in Scotland. Scottish Journal of Geology, 41, 3-11.

MANSELL, M. G. 2003. Rural and Urban Hydrology, London, Thomas Telford.

MARSH, T. J. \& TURTON, P. S. 1996. The 1995 drought - a water resources perspective. Weather, 51, 46-53.

MASON, P. J. 2010. Climate variability in civil infrastructure planning. Proceedings of the Institution of Civil Engineers-Civil Engineering, 163, 74-80.

MAYES, J. 2000. Changing regional climatic gradients in the United Kingdom. Geographical Journal, 166, 125-138. 
MILLY, P. C. D., BETANCOURT, J., FALKENMARK, M., HIRSCH, R. M., ZBIGNIEW, W., KUNDZEWICZ, D., LETTENMAIER, D. P. \& STOUFFER, R. J. 2008. Stationarity is dead: whither water management? Science, 319, 573-574.

MOORE, R. J. 1985. The Probability-Distributed Principle and Runoff Production at Point and Basin Scales. Hydrological Sciences Journal-Journal Des Sciences Hydrologiques, 30, 273-297.

MOORE, R. J. 2007. The PDM rainfall-runoff model. Hydrology and Earth System Sciences, 11, 483-499.

NASH, J. E. \& SUTCLIFFE, J. V. 1970. River flow forecasting through conceptual models part I - A discussion of principles. Journal of Hydrology, 10, 282-290.

ORR, H. G., WILBY, R. L., HEDGER, M. M. \& BROWN, I. 2008. Climate change in the uplands: a UK perspective on safeguarding regulatory ecosystem services. Climate Research, 37, 77-98.

OSBORN, T. J. \& HULME, M. 2002. Evidence for trends in heavy rainfall events over the UK. Philos Trans A Math Phys Eng Sci, 360, 1313-25.

SCOTTISH ENVIRONMENT PROTECTION AGENCY 1997. Policy no.18: Guidelines on setting of compensation flows. Stirling: SEPA.

SINGH, C. R., THOMPSON, J. R., FRENCH, J. R., KINGSTON, D. G. \& MACKAY, A. W. 2010. Modelling the impact of prescribed global warming on runoff from headwater catchments of the Irrawaddy River and their implications for the water level regime of Loktak Lake, northeast India. Hydrology and Earth System Sciences, $14,1745-1765$.

SMITH, K. 1977. Water-Resource Management in Scotland. Scottish Geographical Magazine, 93, 66-79.

SMITH, K. \& BENNETT, A. M. 1994. Recently Increased River Discharge in Scotland Effects on Flow Hydrology and Some Implications for Water Management. Applied Geography, 14, 123-133.

SWEENEY, J. C. \& OHARE, G. P. 1992. Geographical Variations in Precipitation Yields and Circulation Types in Britain and Ireland. Transactions of the Institute of British Geographers, 17, 448-463.

TRIGO, R. M., POZO-VÁZQUEZ, D., OSBORN, T. J., CASTRO-DÍEZ, Y., GÁMIZFORTIS, S. \& ESTEBAN-PARRA, M. J. 2004. North Atlantic oscillation influence on precipitation, river flow and water resources in the Iberian Peninsula. International Journal of Climatology, 24, 925-944.

UK METEOROLOGICAL OFFICE 2006. MIDAS Land Surface Station data (1853-current), [internet], NCAS British Atmospheric Data Centre. Available from http://badc.nerc.ac.uk/view/badc.nerc.ac.uk ATOM dataent ukmo-midas.

WADE, S. D., RANCE, J. \& REYNARD, N. 2013. The UK Climate Change Risk Assessment 2012: Assessing the Impacts on Water Resources to Inform Policy Makers. Water Resources Management, 27, 1085-1109.

WERRITTY, A. \& FOSTER, M. 1998. Climatic variability and recent changes in rainfall and river flows in Scotland. Second International Symposium on Climate and Water. Espoo, Finland

WERRITTY, A. \& SUGDEN, D. 2012. Climate change and Scotland: recent trends and impacts. Earth and Environmental Science Transactions of the Royal Society of Edinburgh, 103, 133-147.

WRIGHT, P. 1995. Water-Resources Management in Scotland. Journal of the Chartered Institution of Water and Environmental Management, 9, 153-163. 


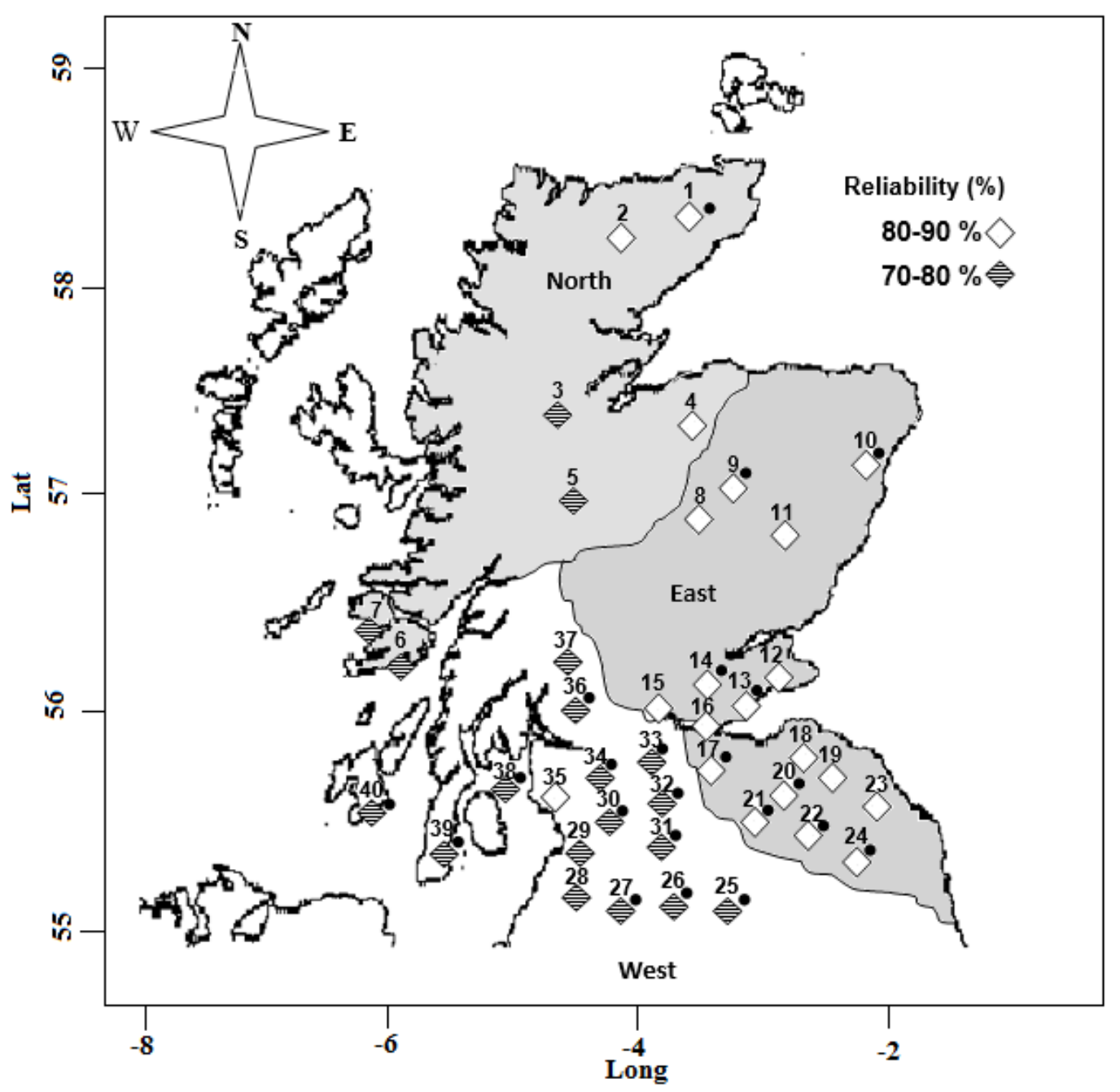

Figure 1 Average reliability of notional reservoirs as calculated at 40 weather stations across Scotland for the period 1976-1990. The 21 weather stations with a solid circle were used in the investigation of rainfall periodicities during the period 1961-2000. Also shown is the division of Scotland into three regions. 


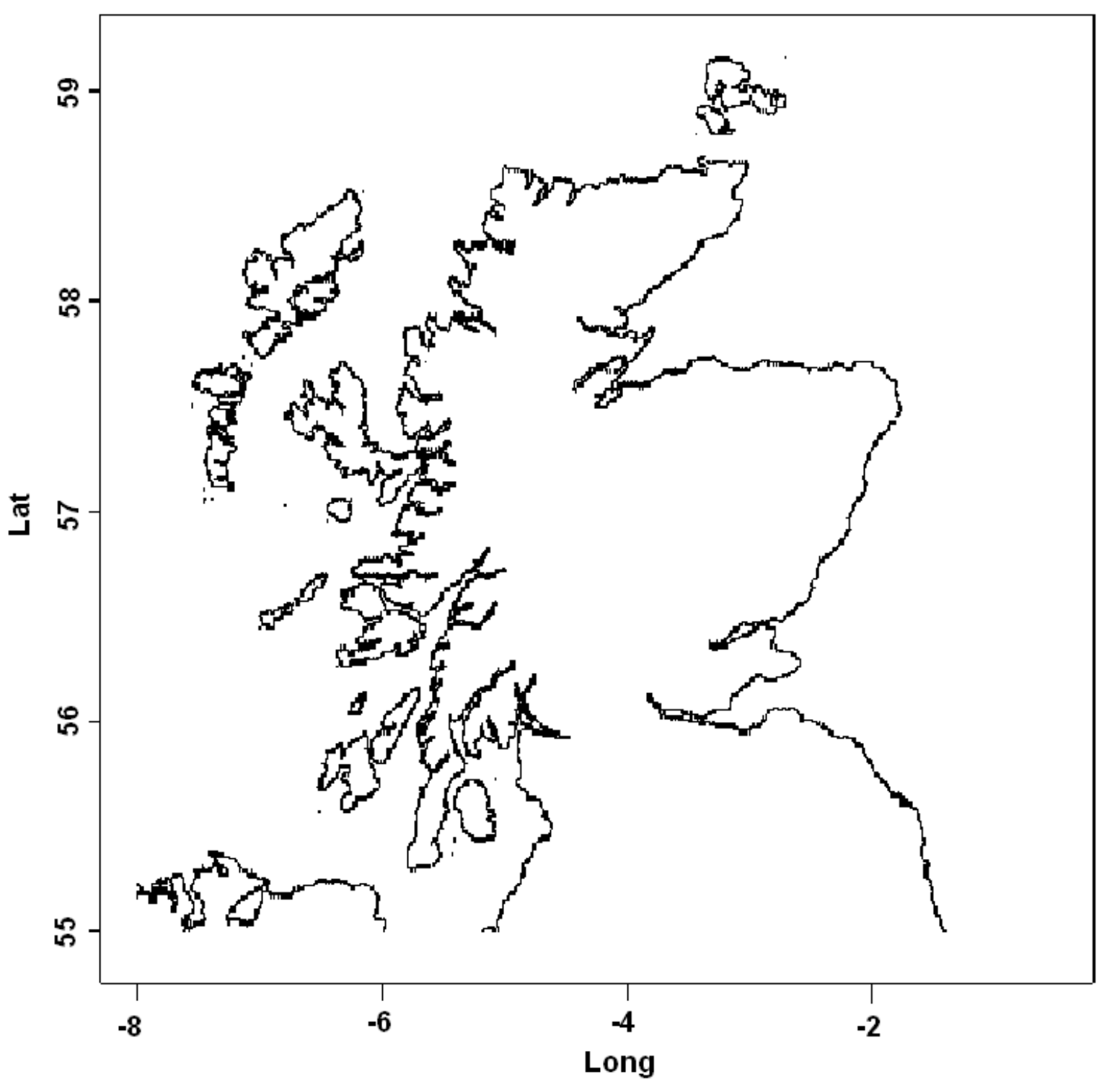




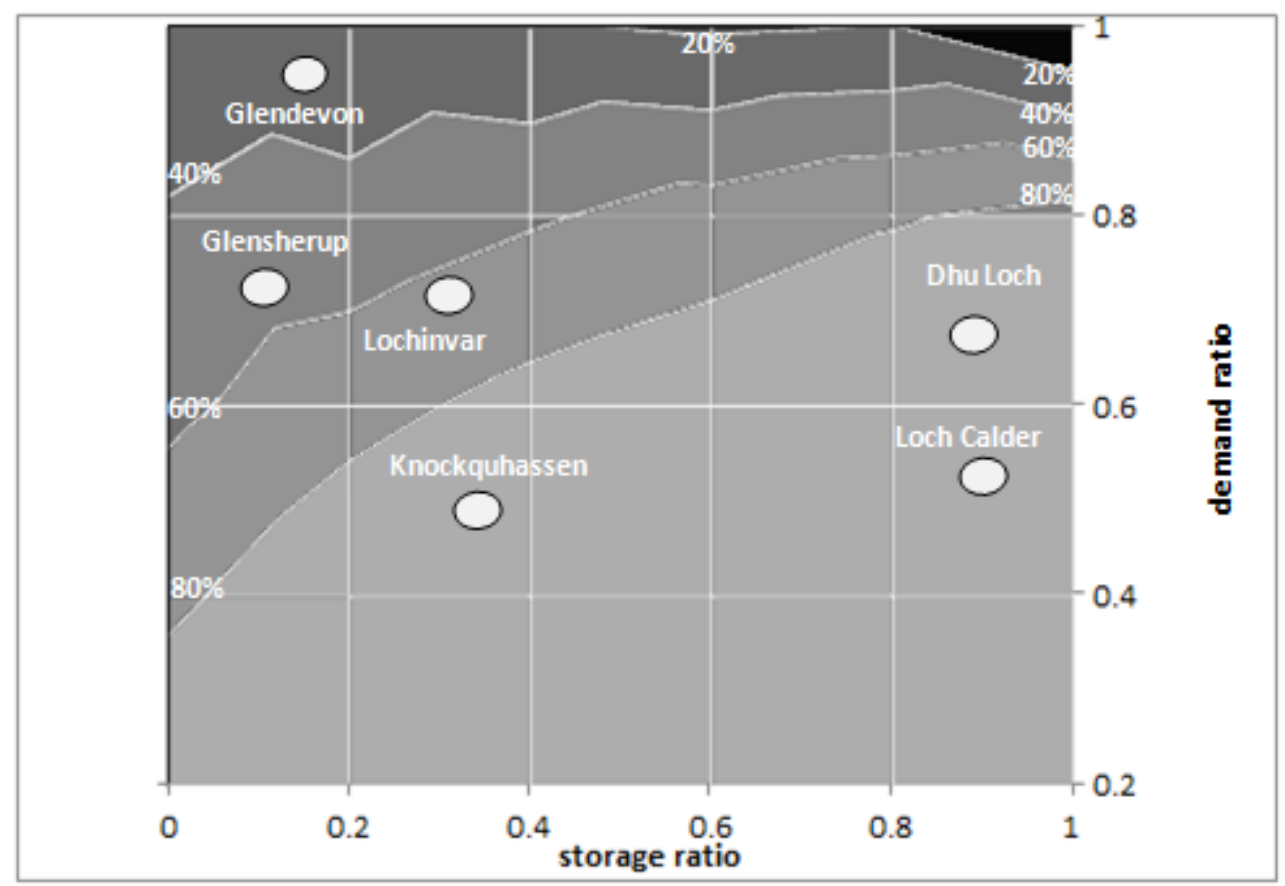

Figure 3 The reliability of the six case study reservoirs based on their storage and demand ratio.

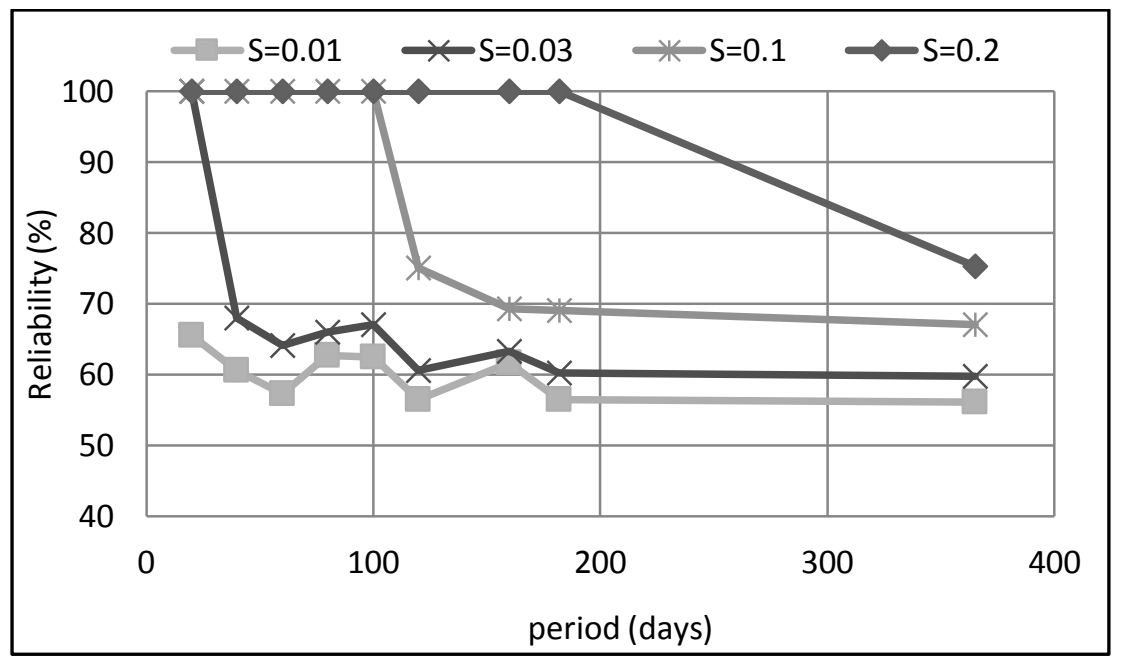

Figure 4 The relationship between reliability and the period of a cosine input to a reservoir for different arbitrary reservoir storage ratios, $S$, and assuming a demand ratio of 0.9. 


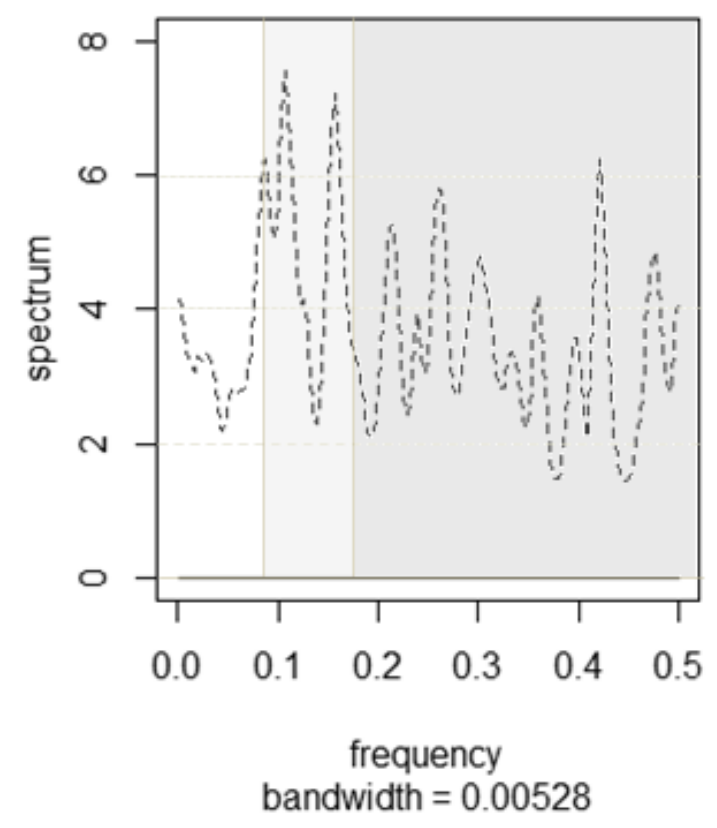

Figure 5 Periodogram of the de-trended precipitation anomaly time series at Dunside for the period 1961-2000. Also shown are the three ranges of periodicities referred to in the text, i.e., $>12$ months, between 6 and 12 months, and $<6$ months.

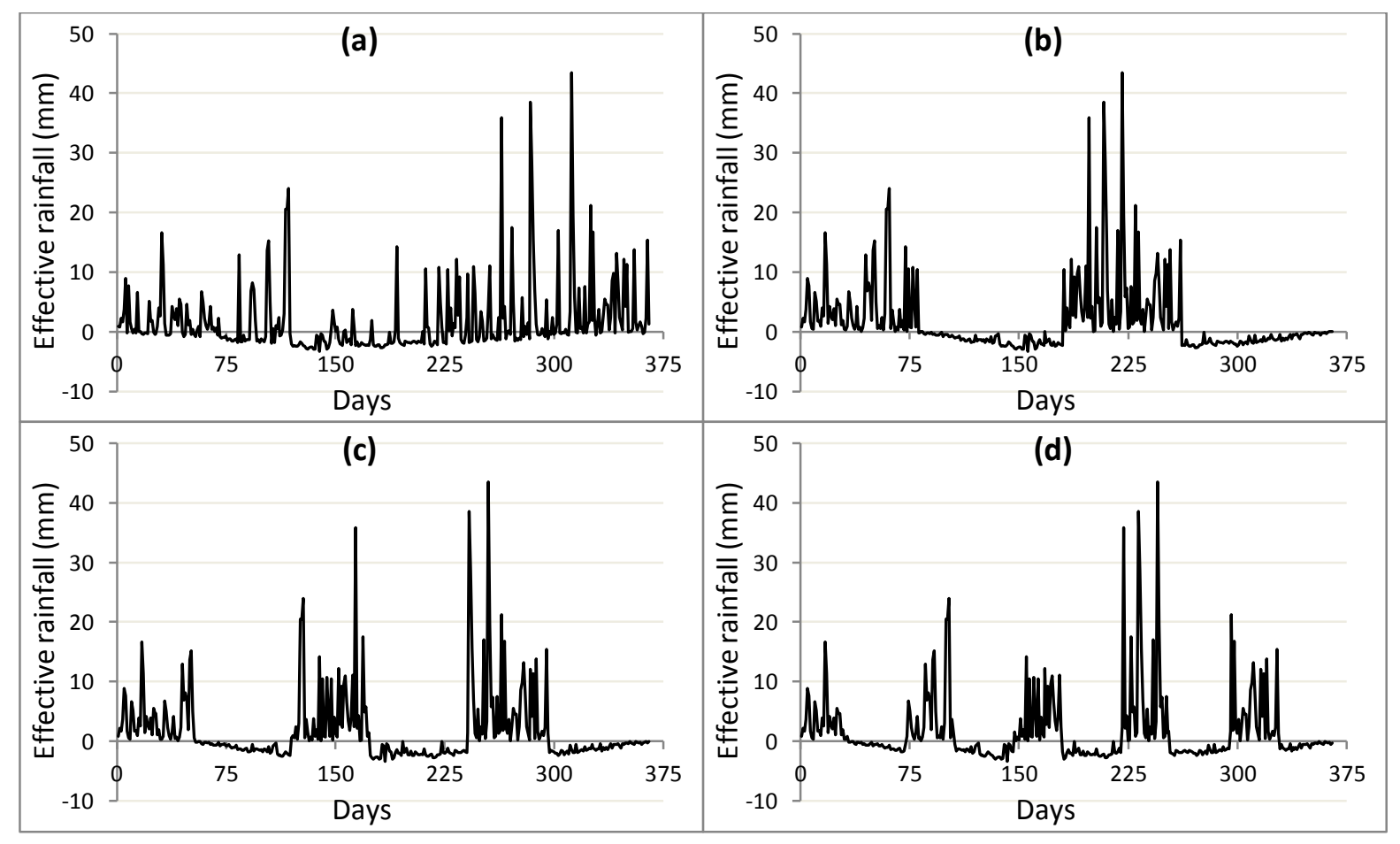

Figure 6 Original effective rainfall time series at Balmoral (a) and examples of re-sequencing of that rainfall time series with two (b), three (c), and five (d) rainy seasons per year. 


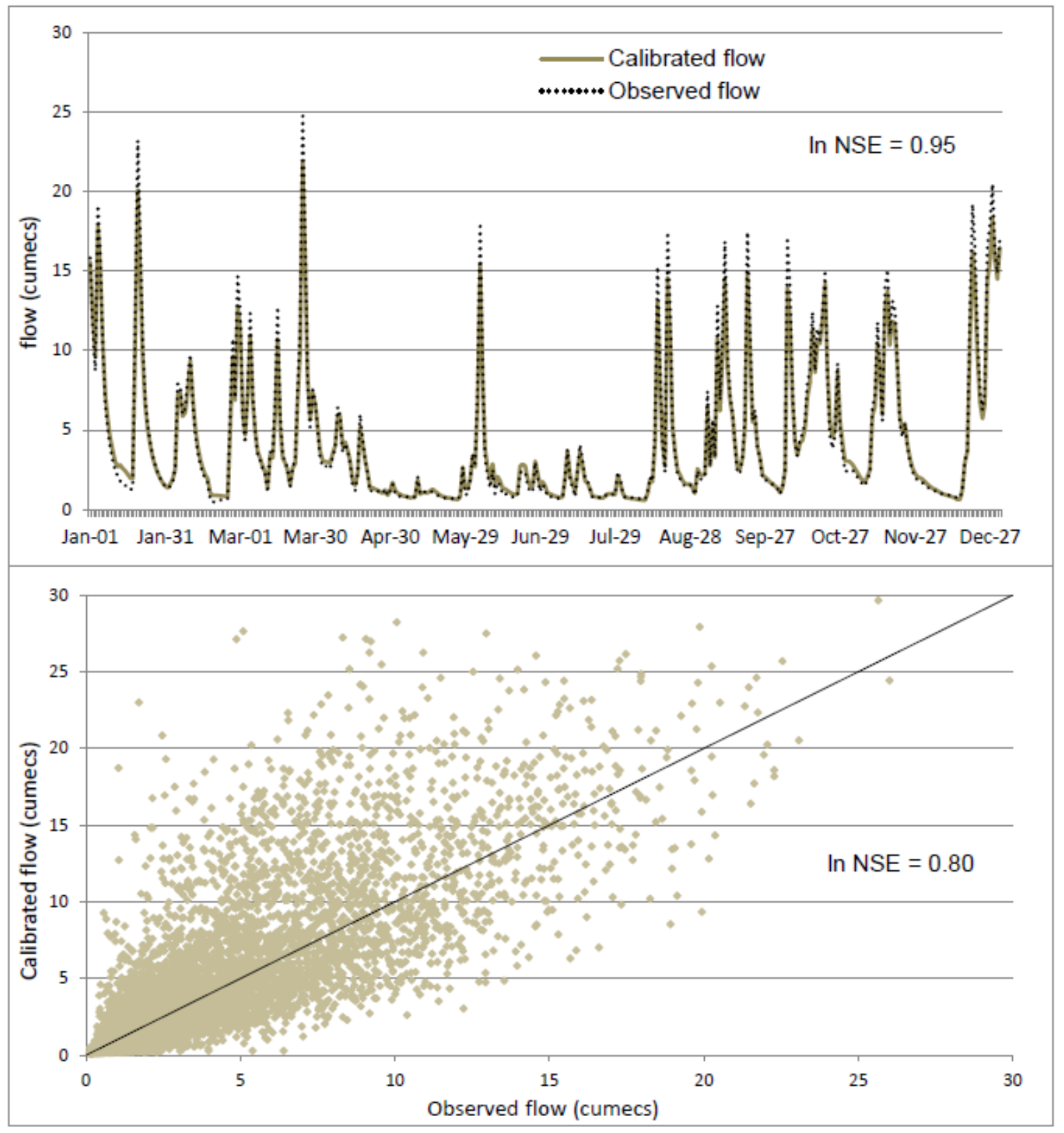

Figure 4 Simulated and observed flow of the Black Cart river flow for the year 1987 (top) and the relationship between the simulated and observed flow of the same river during the period 1968-1987. 


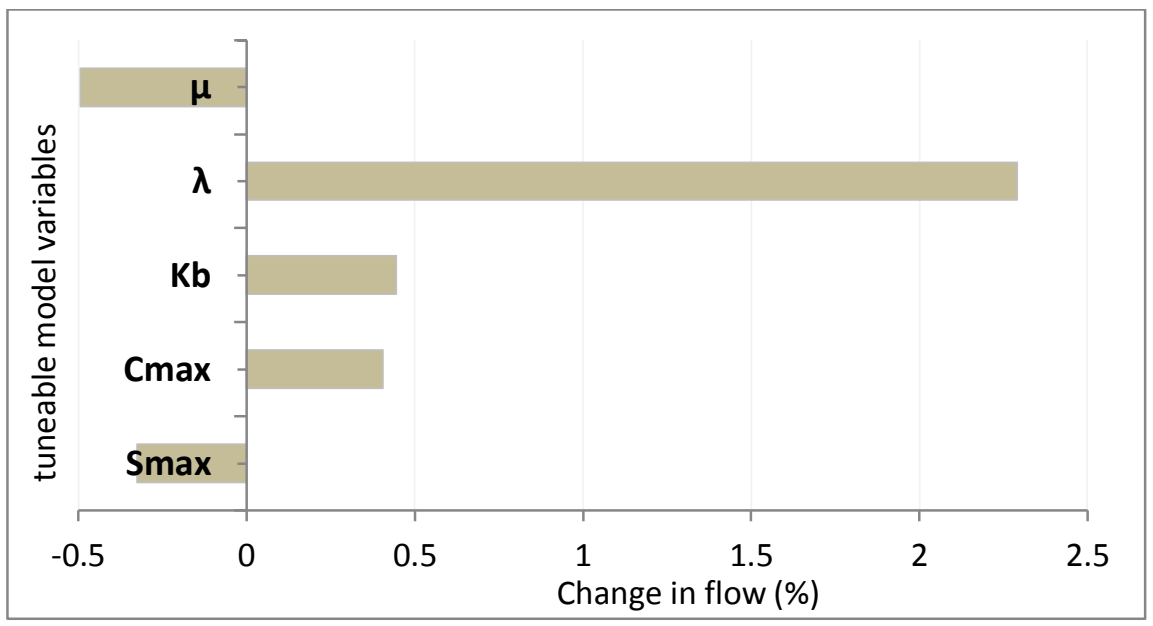

Figure 8 Sensitivity analyses on the five tuneable parameters of the R-R model observed over the Black Cart catchment. The variable $\mu$ is the mean translation time, $\lambda$ is the translation diffusion coefficient, $\mathrm{k}_{\mathrm{b}}$ is the soil drainage coefficient, $\mathrm{C}_{\max }$ is the maximum soil moisture storage capacity over the catchment, and $\mathrm{S}_{\max }$ is the maximum soil moisture storage integrated over the catchment.

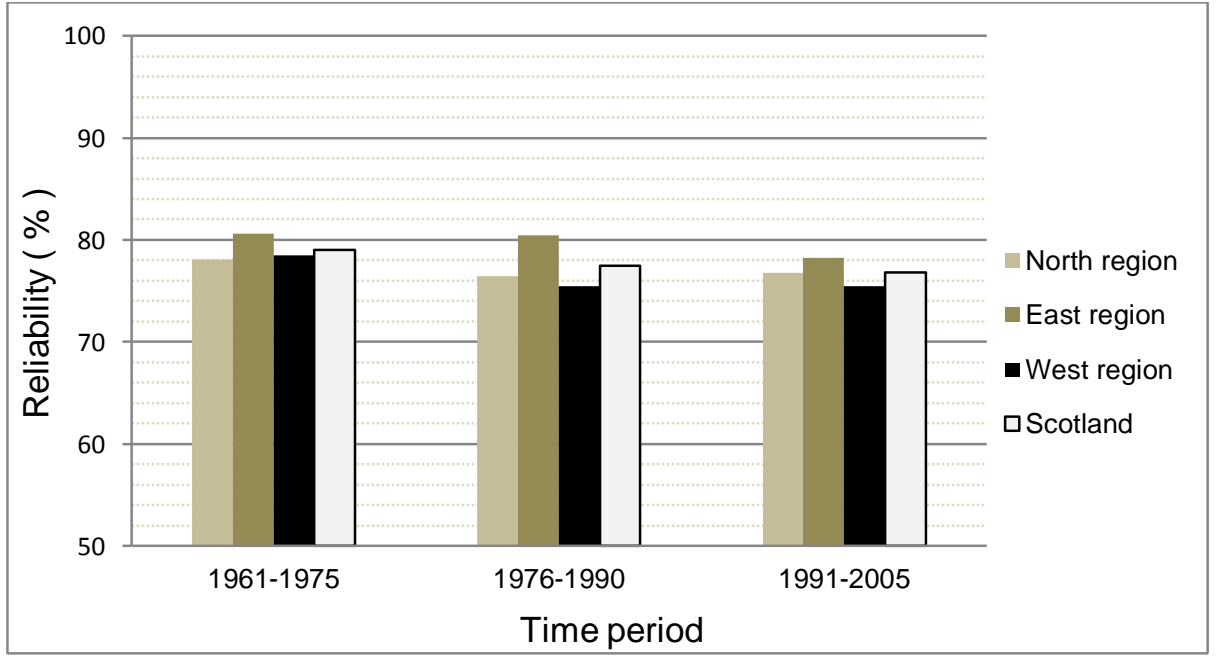

Figure 9 Changes in the reliability of the notional reservoirs during the period 1961-2005. 


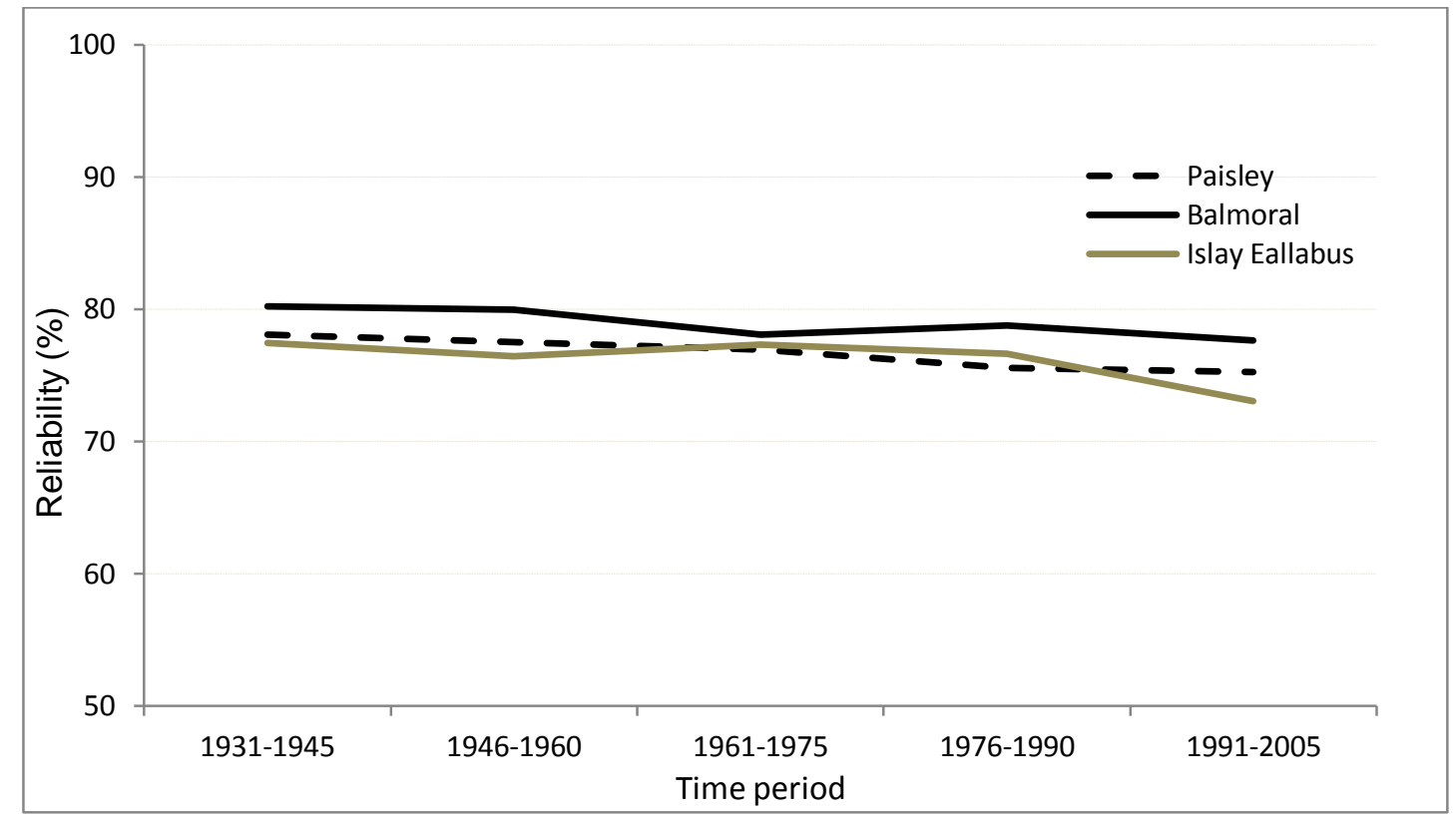

Figure 10 Changes in the reliability of three notional reservoirs during the period 1931-2005. 


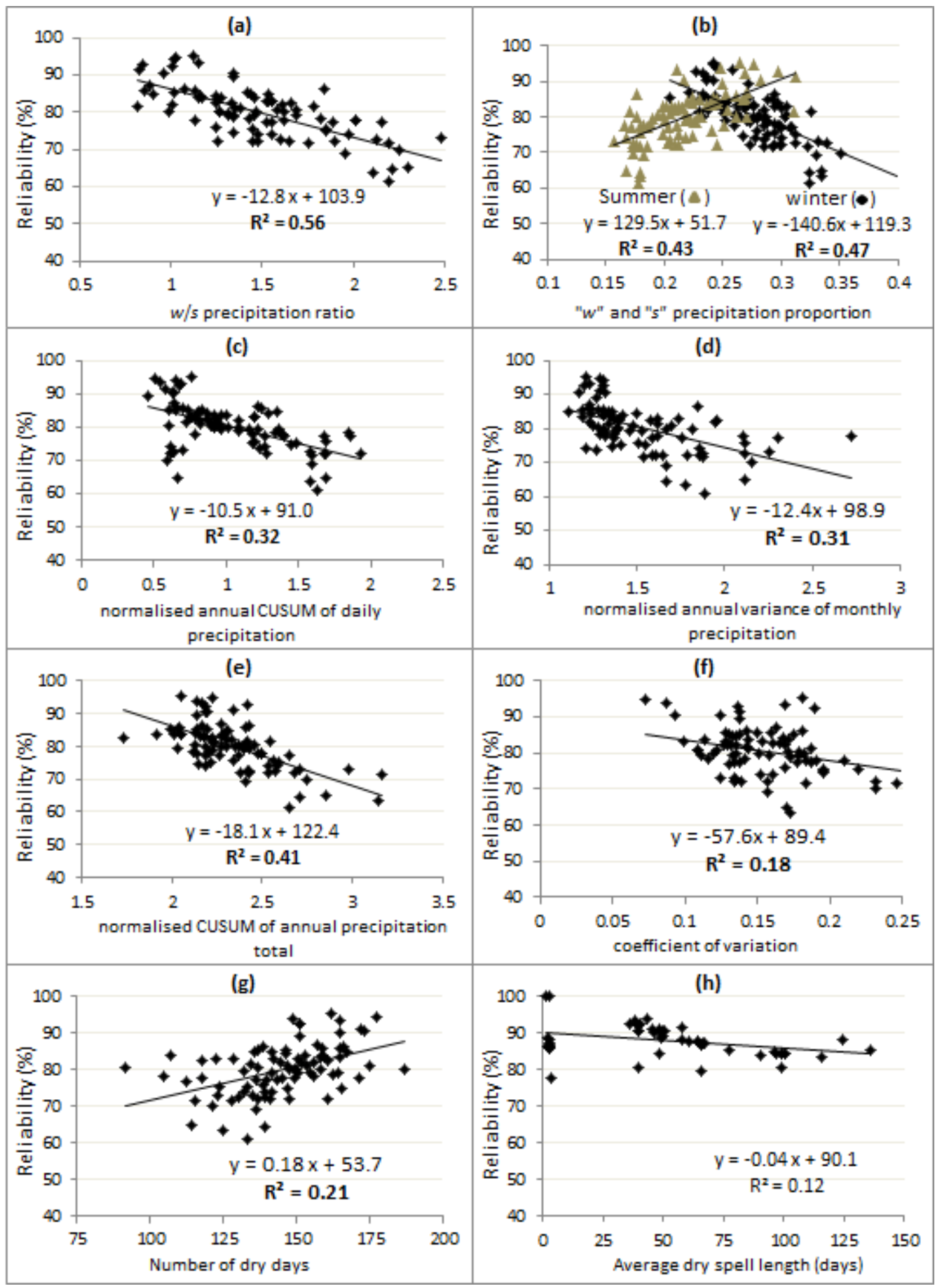

Figure 11 Relationship between the reliability of a notional reservoir having the mean characteristics of the six case study reservoirs and various measures of rainfall variability: w/s ratio of precipitation (a), ratios of winter $(w)$ and summer $(s)$ precipitation to total annual precipitation (b), normalised intra-annual CUSUM range (c), normalised intra-annual variance (d), normalised inter-annual CUSUM range (e), coefficient of variation (f), annual number of dry days (g), and average dry spell length (h). Synthetic rainfall data were used in figure $h$. Bold $\mathrm{R}^{2}$ values are statistically significant at the $95 \%$ confidence level. 


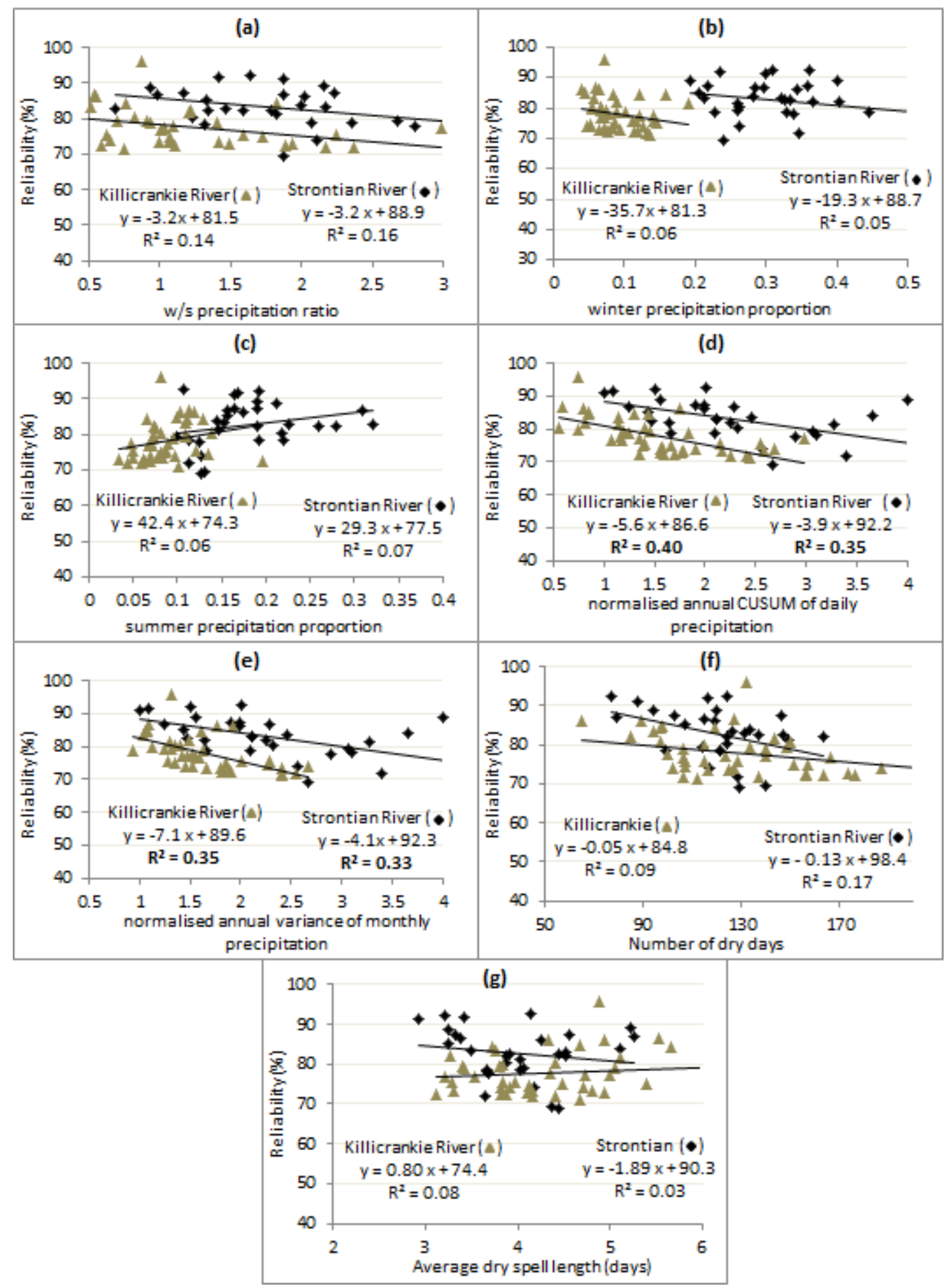

Figure 12 Relationship between the reliability of two river-intake schemes and various measures of rainfall variability: w/s ratio of precipitation (a), ratio of winter precipitation to total annual precipitation (b), ratio of summer precipitation to total annual precipitation (c), normalised intra-annual CUSUM range (d), normalised intra-annual variance (e), annual number of dry days (f), and average dry spell length (g). Synthetic rainfall data were used in figure $g$. Bold $\mathrm{R}^{2}$ values are statistically significant at the $95 \%$ confidence level. 


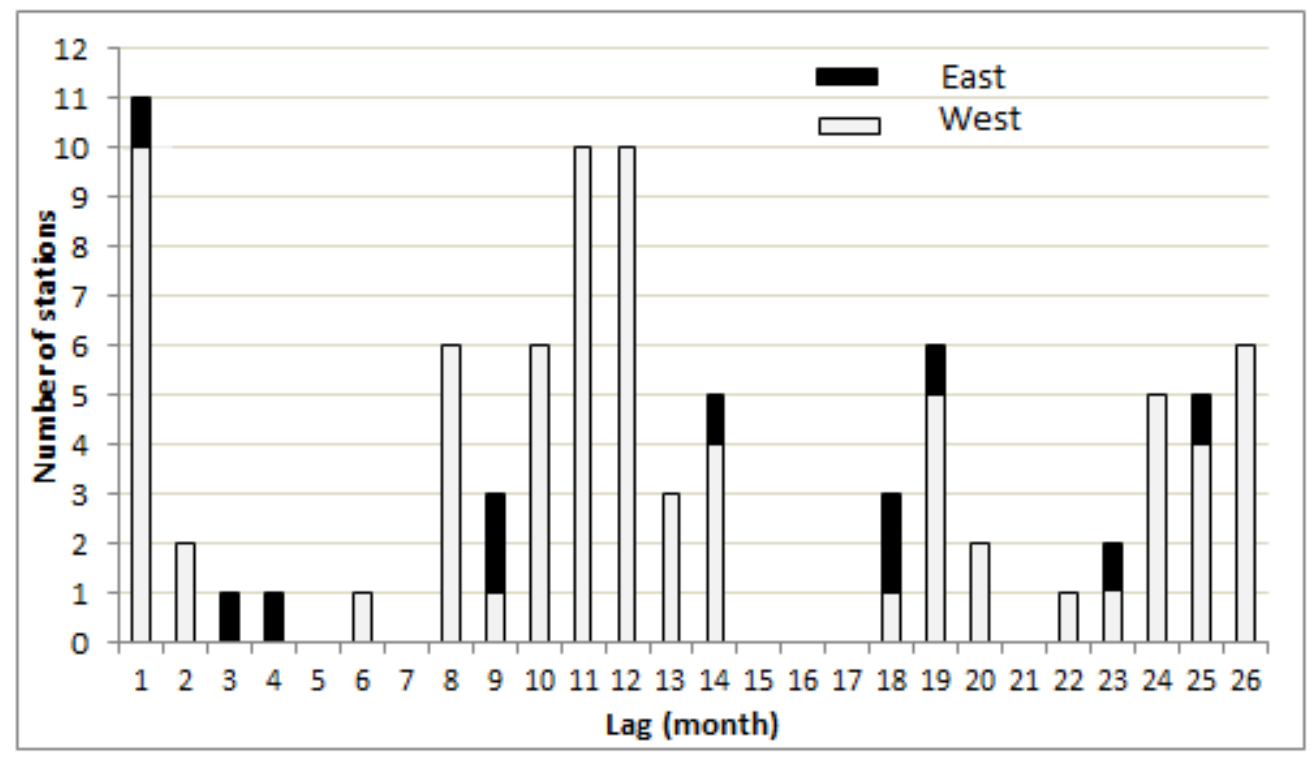

Figure 13 Number of weather stations with statistically significant autocorrelation coefficients of monthly rainfall anomalies at different lags (95\% confident level). 


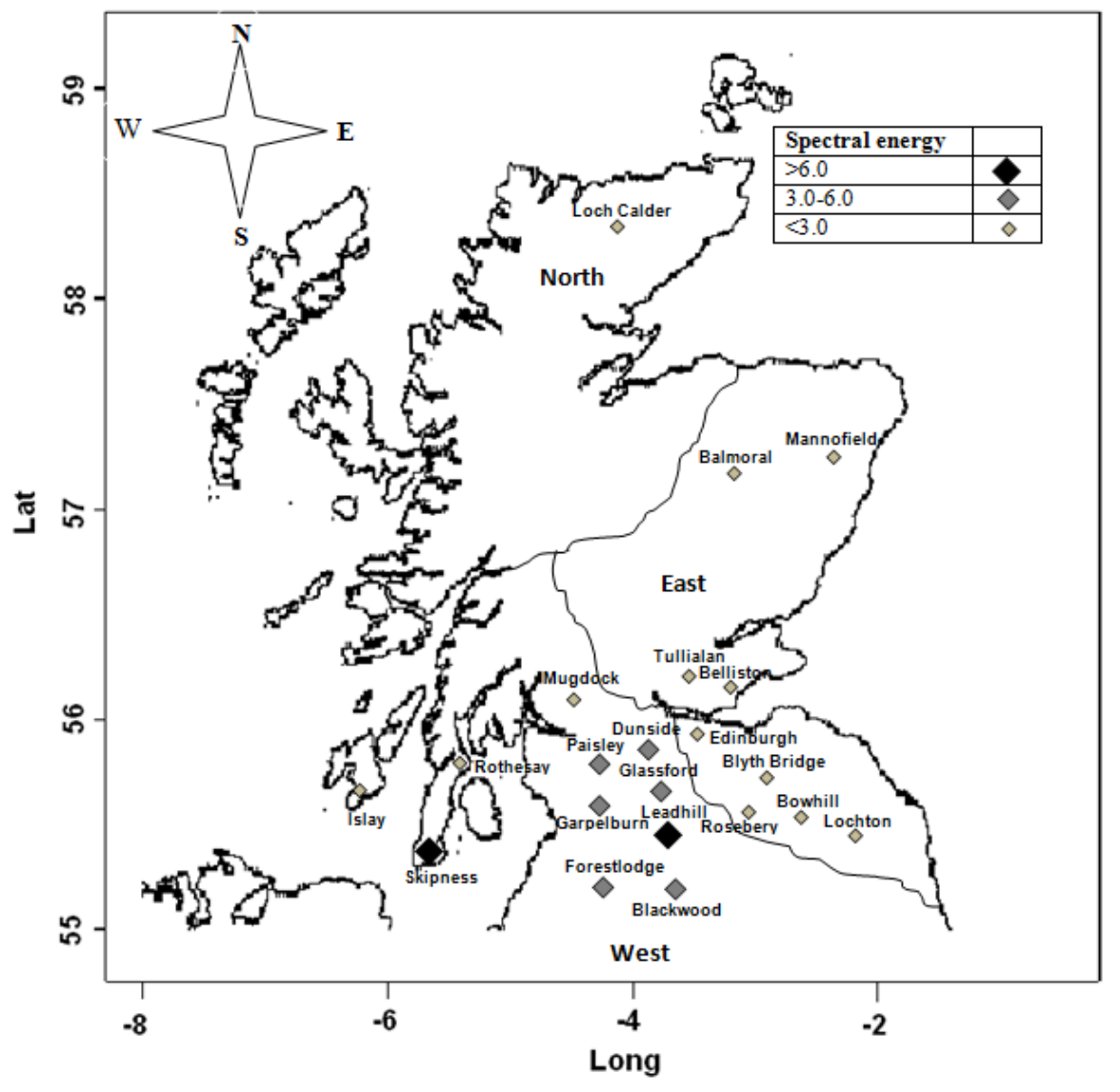

(a) 


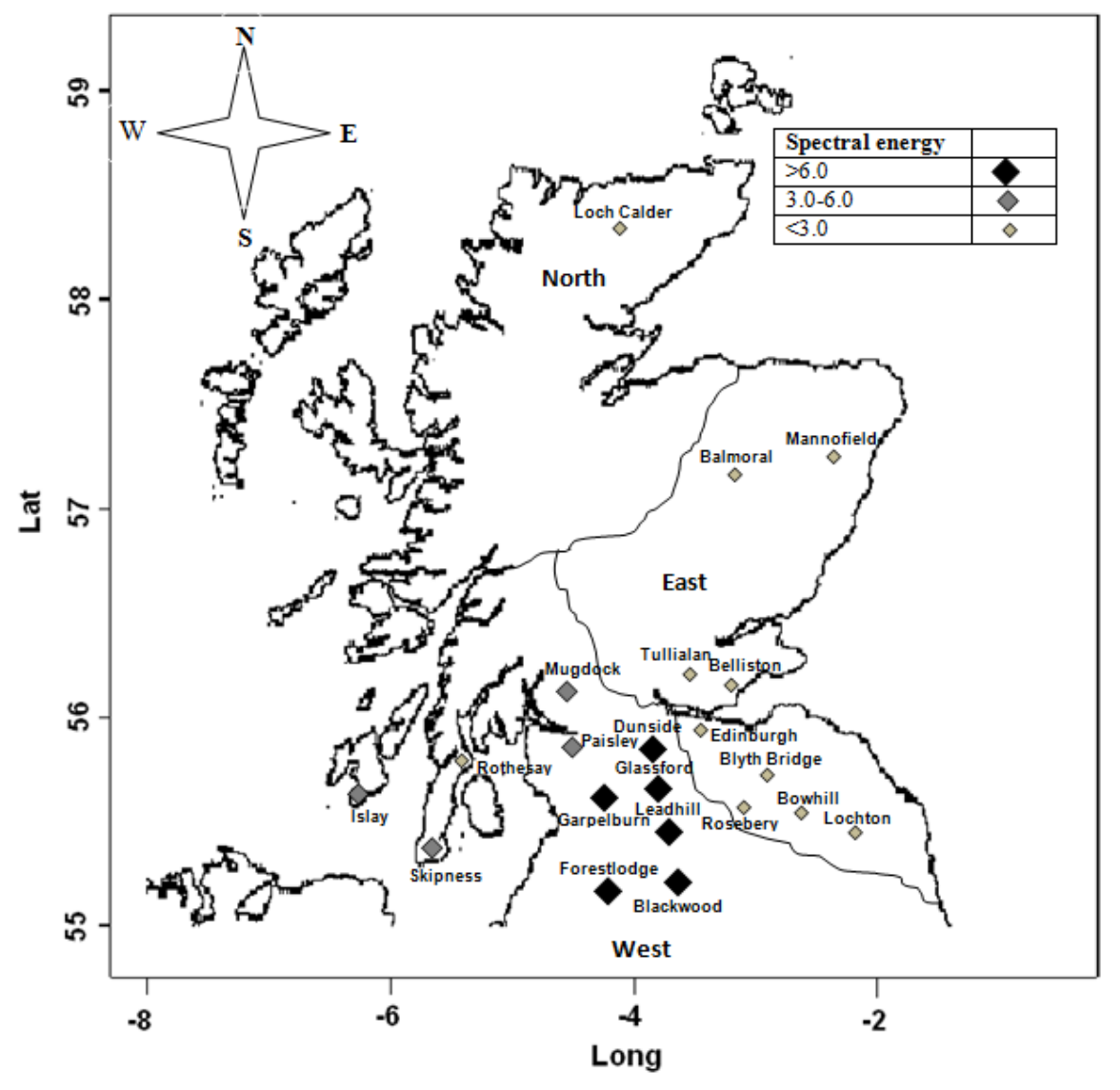

(b)

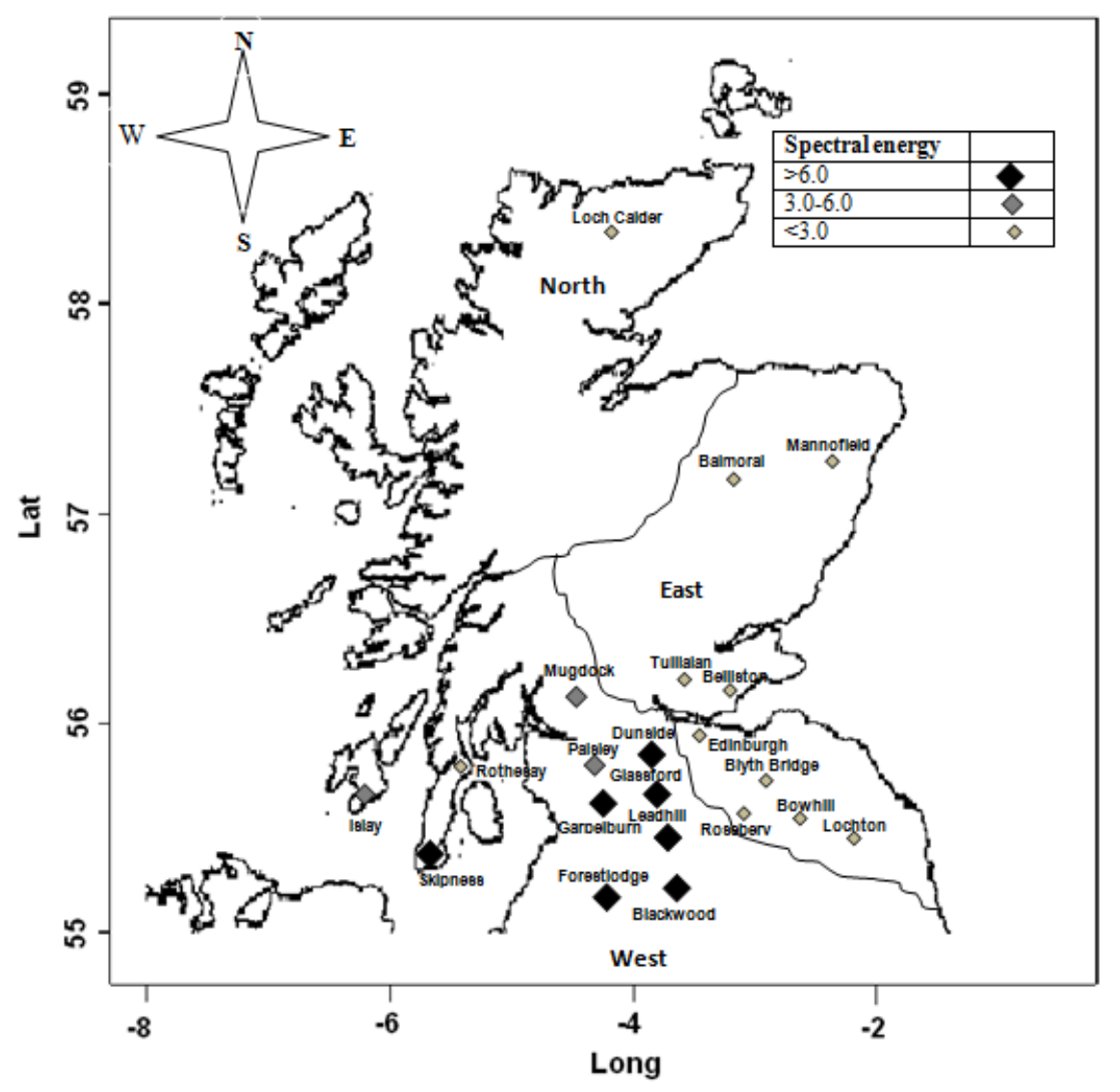


(c)

Figure 14 Peak energy level of rainfall periodicities of less than six months (a), six to twelve months (b), and longer than twelve months (c) observed at 21 weather stations across Scotland during the period 1961-2000.

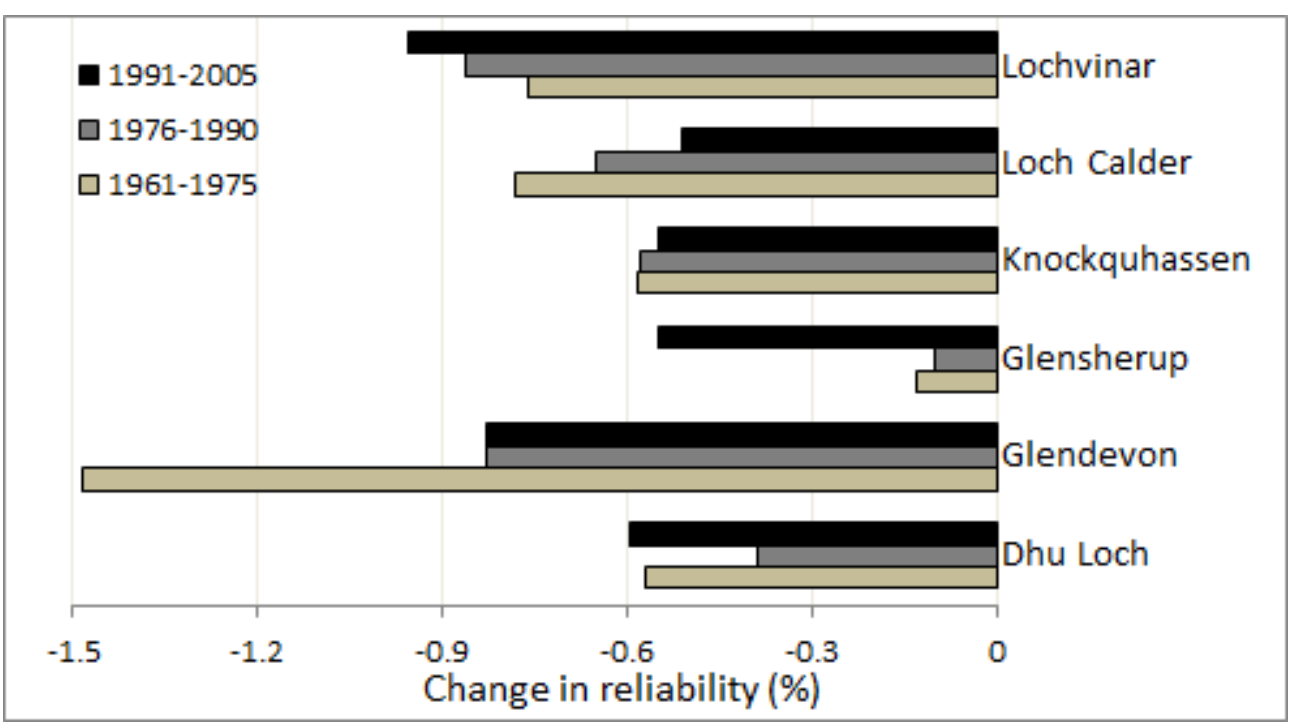

Figure 15 Change in reliability as a result of 5\% increase in evapotranspiration. 
Table 1 The 40 weather stations with mean total annual precipitation

\begin{tabular}{|c|c|c|c|}
\hline Weather station & $\begin{array}{l}\text { Ref. No } \\
\text { Fig. } 1\end{array}$ & $\begin{array}{c}\text { WMO station } \\
\text { number }\end{array}$ & $\begin{array}{c}\text { Total annual } \\
\text { precipitation }^{\mathrm{a}}(\mathrm{mm})\end{array}$ \\
\hline \multicolumn{4}{|l|}{ North of Scotland } \\
\hline Greenland & 1 & 14368 & 999.8 \\
\hline Loch Calder & 2 & 14364 & 983.7 \\
\hline Fairburn & 3 & 14560 & 1034.9 \\
\hline Craggie & 4 & 14705 & 682.7 \\
\hline Cluny Castle & 5 & 14768 & 1146.0 \\
\hline Mull: Gruline & 6 & 14152 & 2120.1 \\
\hline Aros & 7 & 900 & 1090.9 \\
\hline \multicolumn{3}{|l|}{ Regional average } & 953.8 \\
\hline \multicolumn{4}{|l|}{ East of Scotland } \\
\hline Braemar & 8 & 147 & 921.3 \\
\hline Balmoral & 9 & 148 & 844.2 \\
\hline Mannofield & 10 & 163 & 771.2 \\
\hline Invercannie & 11 & 14964 & 849.3 \\
\hline Cameron & 12 & 15393 & 823.4 \\
\hline Belliston & 13 & 237 & 762.5 \\
\hline Tulliallan & 14 & 15450 & 854.3 \\
\hline Tillicoultry & 15 & 15601 & 1030.7 \\
\hline Kirkcaldy & 16 & 15439 & 820.0 \\
\hline Edinburgh & 17 & 251 & 715.1 \\
\hline Samuelston & 18 & 15844 & 619.1 \\
\hline Dunglass & 19 & 15876 & 674.9 \\
\hline Blyth Bridge & 20 & 274 & 905.5 \\
\hline Rosebery & 21 & 15782 & 894.1 \\
\hline Bowhill & 22 & 279 & 909.2 \\
\hline Rawburn & 23 & 16057 & 907.0 \\
\hline Lochton & 24 & 16021 & 638.4 \\
\hline \multicolumn{3}{|l|}{ Regional average } & 743.8 \\
\hline \multicolumn{4}{|l|}{ West of Scotland } \\
\hline Dumfries & 25 & 1017 & 1086.4 \\
\hline Blackwood & 26 & 13224 & 1752.5 \\
\hline Forest Lodge & 27 & 13290 & 2042.1 \\
\hline Drumjohn & 28 & 13281 & 1807.0 \\
\hline Gailes & 29 & 13419 & 1016.7 \\
\hline Garpel Burn & 30 & 13378 & 1749.7 \\
\hline Leadhills & 31 & 983 & 1742.3 \\
\hline Glassford & 32 & 13588 & 1278.1 \\
\hline Dunside & 33 & 13569 & 1454.8 \\
\hline Paisley & 34 & 968 & 1234.9 \\
\hline Loch Thom & 35 & 13502 & 1849.4 \\
\hline Mugdock & 36 & 13632 & 1369.6 \\
\hline Stronachlachar & 37 & 15523 & 2341.2 \\
\hline Bute: Rothesay & 38 & 939 & 1471.8 \\
\hline Skipness & 39 & 13845 & 1504.3 \\
\hline Islay: Eallabus & 40 & 13878 & 1374.1 \\
\hline \multicolumn{3}{|l|}{ Regional average } & 1385.1 \\
\hline
\end{tabular}

${ }^{a}$ Calculated over the period 1976-1990 
Table 2 Analysis of the efficiency of the R-R model

\begin{tabular}{|l|c|c|c|c|c|}
\hline Catchments & $\begin{array}{c}\text { Surface } \\
\text { area } \\
\left(\mathrm{km}^{2}\right)\end{array}$ & $\begin{array}{c}\text { Calibration } \\
\text { time-period }\end{array}$ & $\begin{array}{c}\text { ln } \\
\text { NSE* }\end{array}$ & $\begin{array}{c}\text { Validation } \\
\text { time-period }\end{array}$ & $\begin{array}{c}\text { ln } \\
\text { NSE* }\end{array}$ \\
\hline Strathy at Strathy Bridge & 111.8 & $1991-1997$ & 0.66 & $1998-2004$ & 0.53 \\
\hline Strathmore at Allnabad & 105.0 & $1988-1995$ & 0.55 & $1996-2003$ & 0.57 \\
\hline Brothock Water at Arbroath & 50.0 & $1989-1995$ & 0.55 & $1996-2002$ & 0.51 \\
\hline Craigmill Burn at Craigmill & 29.0 & $1987-1993$ & 0.72 & $1994-2000$ & 0.64 \\
\hline Eden at Strathmiglo & 26.0 & $1991-1995$ & 0.64 & $1996-2000$ & 0.58 \\
\hline $\begin{array}{l}\text { Black Cart Water at Milliken } \\
\text { Park }\end{array}$ & 103.1 & $1968-1987$ & 0.80 & $1988-2006$ & 0.71 \\
\hline Carradale at Dippen & 58.5 & $1996-2001$ & 0.75 & $2002-2007$ & 0.70 \\
\hline Water of Fleet at Rusko & 77.0 & $1988-1992$ & 0.77 & $1993-1998$ & 0.66 \\
\hline
\end{tabular}

${ }^{*}$ The Nash-Sutcliffe Efficiency (NSE) coefficient was calculated using daily data

Table 3 Sensitivity analysis examining the change in evapotranspiration resulting from a $15 \%$ increase in the value of each climatic variable used to estimate it.

\begin{tabular}{|l|c|}
\hline Climate variable & $\begin{array}{l}\text { Change in } \\
\text { evapotranspiration }(\%)\end{array}$ \\
\hline Temperature & 9.5 \\
\hline Sunshine duration & 10.6 \\
\hline Wind speed & 5.3 \\
\hline
\end{tabular}

